\title{
Aircraft measurements of gravity waves in the upper troposphere and lower stratosphere during the START08 field experiment
}

\author{
Fuqing Zhang ${ }^{1}$, Junhong Wei ${ }^{1}$, Meng Zhang ${ }^{1}$, K. P. Bowman ${ }^{2}$, L. L. Pan ${ }^{3}$, E. Atlas ${ }^{4}$, and S. C. Wofsy \\ ${ }^{1}$ Department of Meteorology, The Pennsylvania State University, University Park, Pennsylvania, USA \\ ${ }^{2}$ Department of Atmospheric Sciences, Texas A\&M University, College Station, Texas, USA \\ ${ }^{3}$ National Center for Atmospheric Research, Boulder, Colorado, USA \\ ${ }^{4}$ Rosenstiel School of Marine and Atmospheric Science, University of Miami, Miami, Florida, USA \\ ${ }^{5}$ Division of Engineering and Applied Science/Department of Earth and Planetary Science, \\ Harvard University, Cambridge, Massachusetts, USA \\ Correspondence to: Fuqing Zhang (fzhang@psu.edu)
}

Received: 4 November 2014 - Published in Atmos. Chem. Phys. Discuss.: 20 February 2015

Revised: 27 May 2015 - Accepted: 29 June 2015 - Published: 14 July 2015

\begin{abstract}
This study analyzes in situ airborne measurements from the 2008 Stratosphere-Troposphere Analyses of Regional Transport (START08) experiment to characterize gravity waves in the extratropical upper troposphere and lower stratosphere (ExUTLS). The focus is on the second research flight (RF02), which took place on 21-22 April 2008. This was the first airborne mission dedicated to probing gravity waves associated with strong upper-tropospheric jet-front systems. Based on spectral and wavelet analyses of the in situ observations, along with a diagnosis of the polarization relationships, clear signals of mesoscale variations with wavelengths $\sim 50-500 \mathrm{~km}$ are found in almost every segment of the $8 \mathrm{~h}$ flight, which took place mostly in the lower stratosphere. The aircraft sampled a wide range of background conditions including the region near the jet core, the jet exit and over the Rocky Mountains with clear evidence of vertically propagating gravity waves of along-track wavelength between 100 and $120 \mathrm{~km}$. The power spectra of the horizontal velocity components and potential temperature for the scale approximately between $\sim 8$ and $\sim 256 \mathrm{~km}$ display an approximate $-5 / 3$ power law in agreement with past studies on aircraft measurements, while the fluctuations roll over to a -3 power law for the scale approximately between $\sim 0.5$ and $\sim 8 \mathrm{~km}$ (except when this part of the spectrum is activated, as recorded clearly by one of the flight segments). However, at least part of the high-frequency signals with sampled periods of $\sim 20-\sim 60 \mathrm{~s}$ and wavelengths of $\sim 5-\sim 15 \mathrm{~km}$ might be due to intrinsic observational errors in the aircraft mea-
\end{abstract}

surements, even though the possibilities that these fluctuations may be due to other physical phenomena (e.g., nonlinear dynamics, shear instability and/or turbulence) cannot be completely ruled out.

\section{Introduction}

One of the challenges to understanding the extratropical upper troposphere and lower stratosphere (ExUTLS) is that dynamical processes with a wide range of scales occur in the region. Gravity waves, in particular, are known to play a significant role in determining the structure and composition of the ExUTLS. Tropopause jets and fronts are significant sources of gravity waves (O'Sullivan and Dunkerton, 1995; Reeder and Griffiths, 1996; Zhang, 2004; Wang and Zhang, 2007; Mirzaei et al., 2014; Wei and Zhang, 2014, 2015), along with surface topography (Smith, 1980) and moist convection (Lane et al., 2001). Gravity waves above the jet may be responsible for double or multiple tropopauses (Yamanaka et al., 1996; Pavelin et al., 2001) and may contribute to layered ozone or potential vorticity structures (Bertin et al., 2001). Also, strong horizontal and vertical shear in the layer and the discontinuity in static stability at the tropopause provide a favorable environment to reflect, capture, break and dissipate gravity waves generated in the lower troposphere, such as those produced by surface fronts (Plougonven and Snyder, 2007). Gravity wave breaking and wave-induced turbulence 
(e.g., Koch et al., 2005) can contribute significantly to mixing of trace gases in the ExUTLS, thereby affecting chemical composition (Vaughan and Worthington, 2000). Also, convectively generated gravity waves may extend the impact of moist convection far above cloud tops through wave-induced mixing and transport (Lane et al., 2004).

In particular, mesoscale gravity waves with horizontal wavelengths of $\sim 50-\sim 500 \mathrm{~km}$ are known to occur in the vicinity of unbalanced upper-tropospheric jet streaks and on the cold-air side of surface frontal boundaries (Uccellini and Koch, 1987; Plougonven and Zhang, 2014). This phenomenon has been identified repeatedly in both observational studies (Uccellini and Koch, 1987; Schneider, 1990; Fritts and Nastrom, 1992; Ramamurthy et al., 1993; Bosart et al., 1998; Koppel et al., 2000; Rauber et al., 2001; Plougonven et al., 2003) and numerical investigations of the observed cases (Powers and Reed, 1993; Pokrandt et al., 1996; Kaplan et al., 1997; Zhang and Koch, 2000; Zhang et al., 2001, 2003; Koch et al., 2001, 2005; Lane et al., 2004). In addition, idealized simulations of dry baroclinic jet-front systems in a high-resolution mesoscale model have been performed to investigate the generation of mesoscale gravity waves (Zhang, 2004), the sensitivity of mesoscale gravity waves to the baroclinicity of jet-front systems (Wang and Zhang, 2007), and the source of gravity waves with multiple horizontal scales (Lin and Zhang, 2008). Most recently, Wei and Zhang (2014, 2015) studied the characteristics and potential source mechanisms of mesoscale gravity waves in moist baroclinic jetfront systems with varying degree of convective instability.

Advances in space technology provide the means to observe gravity waves in detail. Recent studies have demonstrated that satellites such as Microwave Limb Sounder (MLS) and Advanced Microwave Sounding Unit-A (AMSUA) offer quantitative information of gravity waves in the middle atmosphere (Alexander and Rosenlof, 2003; Wu and Zhang, 2004; Zhang et al., 2013). In addition to satellite measurements, gravity waves are also observed by surface observations (Einaudi et al., 1989; Grivet-Talocia et al., 1999; Koppel et al., 2000), high-resolution radiosonde networks (Vincent and Alexander, 2000; Wang and Geller, 2003; Zhang and Yi, 2007; Gong and Geller, 2010), radars (Vaughan and Worthington, 2000, 2007), and super-pressure balloons (Hertzog and Vial, 2001).

Among the abovementioned observational tools, aircraft have also been widely used as in situ measurements of gravity waves. Probably since Radok (1954), which was one of the first observations of mountain waves with aircraft, past aircraft field campaigns have mainly focused on terraininduced gravity waves (Radok, 1954; Vergeiner and Lilly, 1970; Lilly and Kennedy, 1973; Smith, 1976; Karacostas and Marwitz, 1980; Brown, 1983; Moustaoui et al., 1999; Leutbecher and Volkert, 2000; Poulos et al., 2002; Dornbrack et al., 2002; Doyle et al., 2002; Smith et al., 2008). The recent Terrain-Induced Rotor Experiment (T-REX) in MarchApril 2006 (Grubišić et al., 2008) was the first full research project to use the National Science Foundation (NSF) - National Center for Atmospheric Research (NCAR) Gulfstream V (GV) (Laursen et al., 2006), which has better Global Positioning System (GPS) accuracy than the previous versions. The National Aeronautics and Space Administration (NASA) high-altitude ER-2 research aircraft was also employed during the recent Cirrus Regional Study of Tropical Anvils and Cirrus Layers Florida Area Cirrus Experiment (CRYSTAL-FACE) (Jensen et al., 2004), which conducted research flights in the vicinity of subtropical and tropical deep convection to study the effects of convectively generated gravity waves (Wang et al., 2006). However, systematic in situ measurements of mesoscale gravity waves, especially those associated with upper-tropospheric jet-front systems in the ExUTLS are very scarce. Relevant work includes Nastrom and Fritts (1992) and Fritts and Nastrom (1992), who used commercial aircraft measurements to infer the different sources of gravity waves (convections, front, topography, and jet streaks). They found that mesoscale variances of horizontal wind and temperature were large at the jet-front vicinity regions. However, little is known quantitatively about the generation mechanisms, propagation and characteristics of gravity waves associated with the tropospheric jet streaks. This is due in part to the fact that gravity waves are transient in nature and hard to resolve with regular observing networks (Zhang et al., 2004).

The recent Stratosphere-Troposphere Analyses of Regional Transport 2008 (START08) experiment was conducted to examine the chemical structure of the ExUTLS in relation to dynamical processes spanning a range of scales (Pan et al., 2010). In particular, one specific goal of START08 was to observe the properties of gravity waves generated by multiple sources, including jets, fronts, and topography. During the START08 field campaign, a total of 18 research flight (RF) missions were carried out during April-June 2008 from the NCAR aviation facility in Broomfield, Colorado (also see the online field catalog of the $18 \mathrm{RFs}$ at http://catalog.eol.ucar.edu/start_08/missions/ missions.html). The second flight (RF02), which occurred on 21-22 April 2008, was dedicated, to our knowledge for the first time, to probing mesoscale gravity waves associated with a strong upper-tropospheric jet-front system, even though some previous studies may have recognized the presence of these waves (e.g., Shapiro and Kennedy, 1975; Koch et al., 2005). Although only one flight specifically targeted gravity waves, many of the other flights during START08 obtained high-quality observations of gravity waves in the ExUTLS under a wide range of meteorological conditions. This study is an analysis of the gravity wave observations from the START08 mission.

A brief description of the experimental design for RF02 and its corresponding mesoscale simulation is presented in Sect. 2, followed in Sect. 3 by a review of the flight-level measurements. Section 4 investigates the localized wave variance with wavelet analysis and examines the polarization 
relationship based on cospectrum/quadraspectrum analysis. Several examples of wave-like variances are shown and discussed in Sect. 5. Section 6 contains a summary.

\section{Experimental design}

The GV research aircraft is ideally suited for investigating gravity waves in the ExUTLS region. The flight ceiling of the aircraft is about $14 \mathrm{~km}$ with the START08 payload, which enables sampling the vertical structure of the ExUTLS. With a typical flight speed of $\sim 250 \mathrm{~m} \mathrm{~s}^{-1}$ at cruise altitude, the flight duration of $\sim 8 \mathrm{~h}$ for a single flight enables the $\mathrm{GV}$ to sample a large geographic area with high-resolution $(1 \mathrm{~Hz})$ in situ observations. A total of 68 flight segments (color lines in Fig. 1) during the START08 are selected for analysis (also see Fig. 2 in Pan et al., 2010, for GV ground tracks of the $18 \mathrm{RFs}$ ). Each of these flight segments is longer than $200 \mathrm{~km}$ and has near-constant flight-level static pressure and a relatively straight path. This will largely eliminate spurious wave variance due to rapid changes in direction or altitude. In particular, the RF02 mission was conducted over the central United States $\left(38.87-51.10^{\circ} \mathrm{N}, 94.00-109.95^{\circ} \mathrm{W}\right)$ to study the gravity wave excitation from a jet-front system and topography in the ExUTLS (Fig. 2, Table 1). It started at 17:53 UTC on 21 April 2008 and finished at 02:54 UTC on 22 April 2008 . This $\sim 8 \mathrm{~h}$ flight covered a total horizontal distance of $\sim 6700 \mathrm{~km}$, mostly in the lower stratosphere. Five flight segments (thick blue lines in Fig. 1; thick blue lines in Fig. 2b-f; details in Sect. 3) in RF02 are used here. For most of the five flight segments, the aircraft flew at an altitude of $\sim 12.5 \mathrm{~km}$ (red lines in Fig. 3d; Table 1) and at a speed of $\sim 250 \mathrm{~m} \mathrm{~s}^{-1}$ (Table 1).

The Weather Research and Forecast (WRF) model (Skamarock et al., 2005) was used for flight-planning forecasts. Real-time forecasts used WRF version 2.2.1 and were run with 45 and $15 \mathrm{~km}$ grid spacing for single deterministic forecasts (D1 and D2 in Fig. 1) and $45 \mathrm{~km}$ grid spacing for ensemble prediction (D1 only). The model was initialized with a 30-member mesoscale ensemble-based multi-physics data assimilation system (Zhang et al., 2006; Meng and Zhang, 2008a, b) and assimilated standard radiosonde observations. The real-time WRF forecasts were archived at the START08 field catalog (http://catalog.eol.ucar.edu/cgi-bin/ start08/model/index). The flight track of RF02 was assigned to fly across the jet exit region and gravity wave active area predicted by the real-time forecasts (also see Fig. 11 in Pan et al., 2010, for the real-time mesoscale forecast of gravity waves). Higher-resolution post-mission WRF simulations with 5 and $1.67 \mathrm{~km}$ grid spacing (D3 and D4 in Fig. 1) were also conducted to examine the role of small-scale dynamical processes (e.g., convection and gravity waves), which will be briefly reported in Sect. 3. Nevertheless, an in-depth investigation of the gravity wave dynamics based on the

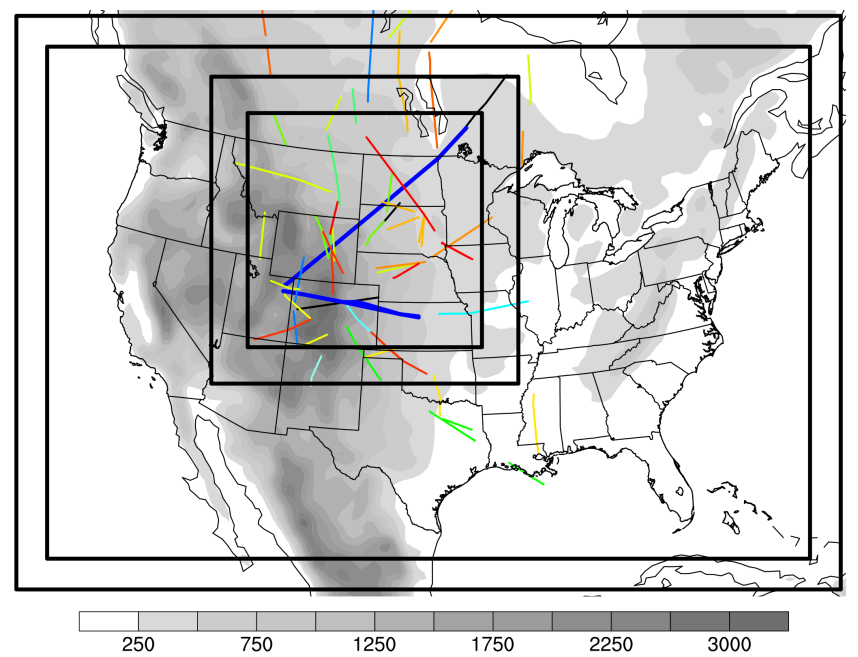

Figure 1. The 68 Gulfstream V (GV) flight segments (colored lines) selected for wave analysis during START08. The 18 colors represent 18 research flight (RF) missions. The thick blue lines represent the second flight (RF02). The gray shadings give the terrain elevation map (shaded every $250 \mathrm{~m}$ ) over North America. The four black boxes are the model domain design for the second research flight (RF02) during 21-22 April 2008, which are named D1-D4 from coarse to fine domain with horizontal resolutions of $45,15,5$ and $1.67 \mathrm{~km}$, respectively. The field catalog of the 18 RFs are available online (at http://catalog.eol.ucar.edu/start_08/ missions/missions.html). The GV ground tracks of the $18 \mathrm{RFs}$ are also documented in Fig. 2 of Pan et al. (2010).

high-resolution post-mission WRF simulations is beyond the scope of the current study, and will be reported elsewhere.

\section{Overview of the flight-level measurements}

Figure 2 depicts the track design of the entire flight and five flight segments during RF02, along with the horizontal wind speed and the smoothed horizontal divergence near the flight level simulated by the high-resolution post-mission WRF simulations valid at different representative times of each of the five segments. Three flight segments pass mainly along an upper-tropospheric jet streak. These are labeled J1, J2, and J3 and are displayed in Fig. 2b, c, and d, respectively. Two other flight segments cross the mountains and high plains of Colorado and Kansas. These are labeled M1 and M2 and are displayed in Fig. 2e and f, respectively. Flight segment $\mathrm{J} 3$ is the longest during RF02. That segment includes flight through or above the jet core (gray shading in Fig. 2), a jet over high mountains (see the terrain map in Fig. 1), the exit region of the jet, and a surface cold front (not shown). The other two segments, $\mathbf{J} 1$ and $\mathbf{J} 2$, were intended to be a single segment, but an altitude change was necessary due to air traffic control.

Guided by the WRF model forecasts (e.g., Fig. 11 in Pan et al., 2010), this GV flight mission sampled WRFpredicted gravity waves with different potential sources in- 


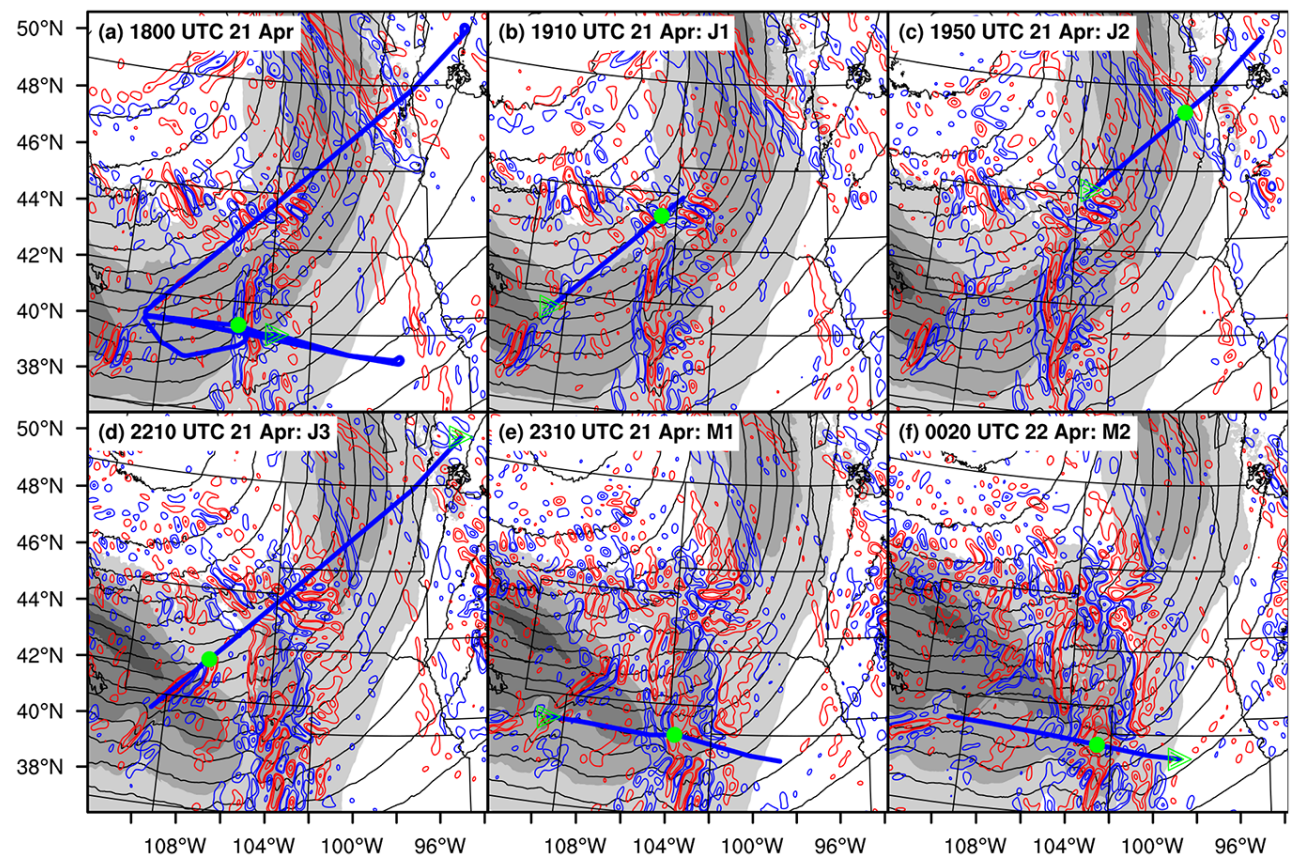

Figure 2. Simulated pressure at $9 \mathrm{~km}$ altitude (black contours; unit in $\mathrm{hPa} ; \Delta=2 \mathrm{hPa}$ ), horizontal wind speed at $9 \mathrm{~km}$ altitude (black shadings; unit in $\mathrm{m} \mathrm{s}^{-1}$; levels at $30,40,50,60 \mathrm{~m} \mathrm{~s}^{-1}$ ), and the mesoscale component of horizontal divergence at $12.5 \mathrm{~km}$ (blue contours, positive; red contour, negative; contour levels at $\pm 7.5, \pm 15, \pm 30, \pm 60 \times 10^{-5} \mathrm{~s}^{-1}$ ) during RF02 in START08, with marked GV flight track (blue line) at the selected time: (a) entire flight track of 21 April 18:00 UTC, (b) segment J1 of 21 April 19:10 UTC, (c) segment J2 of 21 April 19:50 UTC, (d) segment J3 of 21 April 22:10 UTC, (e) segment M1 of 21 April 23:10 UTC, and (f) segment M2 of 22 April 00:20 UTC. The triangle and circle marks represent the aircraft at the start time of the segment and at the selected time. The two-dimensional (2-D) variables are based on D4 in Fig. 1. A bandpass filter is applied to extract signals with wavelengths from 50 to 500 km for horizontal divergence.

Table 1. The aircraft statistic parameters of five selected flight segments in RF02 during the START08 field campaign. Columns 1-7 represent the name, the starting time (s), the ending time (s), the averaged flight height $(\mathrm{km})$, the averaged static pressure (hPa), the total distance $(\mathrm{km})$, and the averaged flight speed $\left(\mathrm{m} \mathrm{s}^{-1}\right)$ of each selected flight segment.

\begin{tabular}{lrrrrrr}
\hline $\begin{array}{l}\text { Flight } \\
\text { segment }\end{array}$ & $\begin{array}{r}\text { Start } \\
(\mathrm{s})\end{array}$ & $\begin{array}{r}\text { End } \\
(\mathrm{s})\end{array}$ & $\begin{array}{r}\text { Averaged flight } \\
\text { height }(\mathrm{km})\end{array}$ & $\begin{array}{r}\text { Averaged static } \\
\text { pressure }(\mathrm{hPa})\end{array}$ & $\begin{array}{r}\text { Distance } \\
(\mathrm{km})\end{array}$ & $\begin{array}{r}\text { Averaged flight } \\
\text { speed }\left(\mathrm{m} \mathrm{s}^{-1}\right)\end{array}$ \\
\hline J1 & 2450 & 5000 & 11.8 & 196.9 & 685.74 & 268.92 \\
J2 & 5170 & 8620 & 12.5 & 178.7 & 908.53 & 263.34 \\
J3 & 9120 & 16850 & 13.1 & 162.1 & 1641.93 & 212.41 \\
M1 & 17100 & 20630 & 12.6 & 178.5 & 950.46 & 269.25 \\
M2 & 21500 & 26430 & 11.0 & 227.6 & 946.90 & 192.07 \\
\hline
\end{tabular}

cluding imbalance of jet streak and orographic forcing. Figure 3 shows the along-track horizontal velocity component $(u)$, across-track horizontal velocity component $(v)$, horizontal wind speed $\left(V ; V=\sqrt{u^{2}+v^{2}}\right)$, vertical velocity component $(w)$, potential temperature $(\theta)$, corrected static pressure $\left(p_{\mathrm{c}}\right)$, static pressure $\left(p_{\mathrm{s}}\right)$, hydrostatic pressure correction $\left(p_{\mathrm{h}}\right)$ derived from the airborne in situ measurements as well as flight height, and terrain along each of the five flight segments. To facilitate spectral and wavelet analyses of these measurements, each variable from the $1 \mathrm{~Hz}$ aircraft measurement along the flight segment is linearly interpolated into $250 \mathrm{~m}$ spatial series with fixed resolution in dis- tance. The right-hand rule is used to determine the relationships among the positive along-track directions, the positive across-track directions, and the positive vertical directions. For segments $\mathrm{J} 1, \mathrm{~J} 2$, and $\mathrm{J} 3$, the positive along-track (acrosstrack) directions are all approximately toward the northeast (northwest). For segments M1 and M2, the positive alongtrack (across-track) directions are both approximately toward the east (north). The corrected static pressure $p_{\mathrm{c}}$ is calculated using the formula of Smith et al. (2008, their Eq. 12):

$$
p_{\mathrm{c}}=p_{\mathrm{s}}+p_{\mathrm{h}}=p_{\mathrm{s}}+\bar{\rho} g\left(z-z_{\mathrm{ref}}\right)
$$



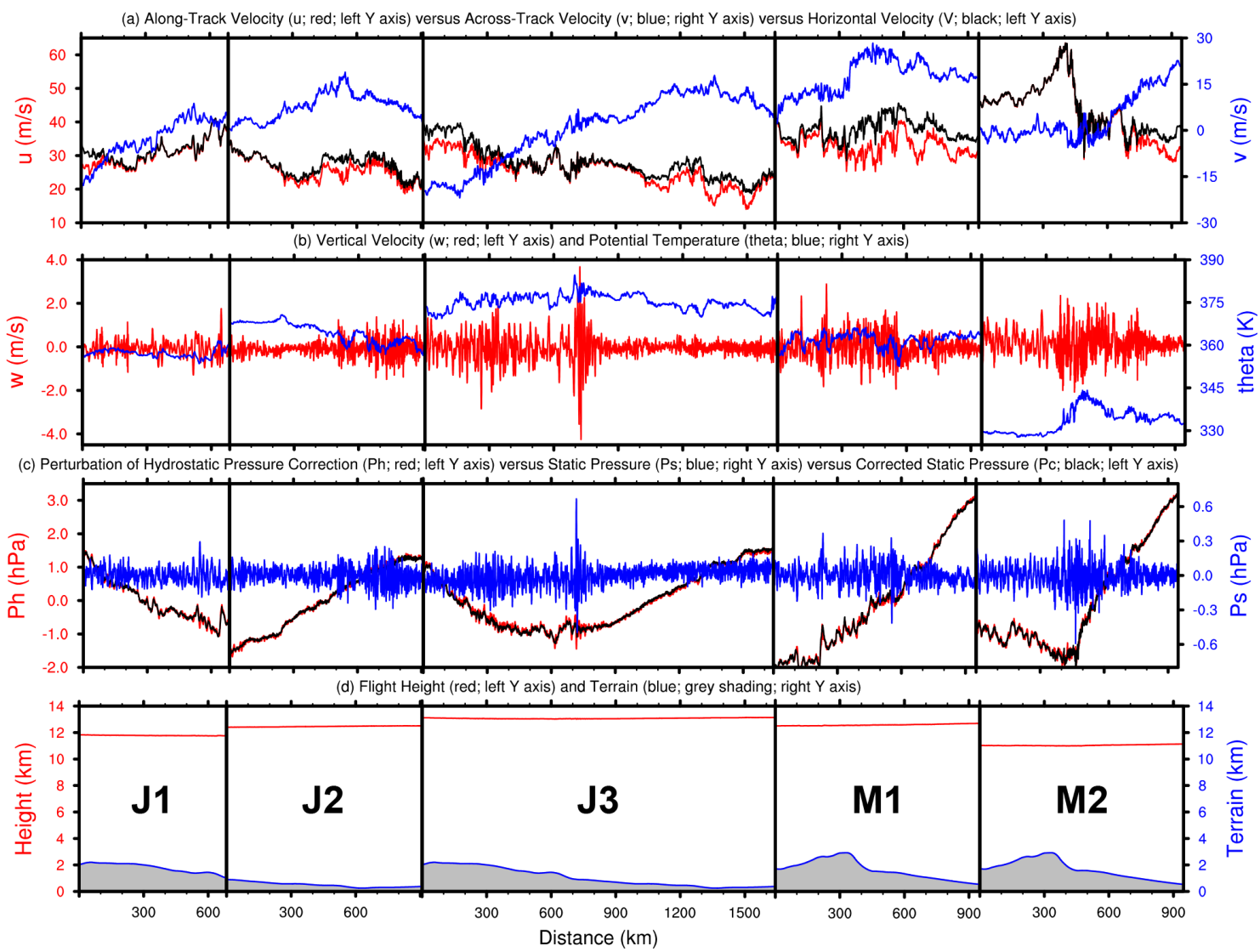

Figure 3. GV flight-level aircraft measurements during five selected segments (from left to right: J1, J2, J3, M1 and M2) of RF02 in START08: (a) along-track velocity component (red; unit in $\mathrm{m} \mathrm{s}^{-1}$; left $y$ axis), across-track velocity component (blue; unit in $\mathrm{m} \mathrm{s} \mathrm{s}^{-1}$; right $y$ axis) and horizontal velocity component (black; unit in $\mathrm{m} \mathrm{s}^{-1}$; left $y$ axis); (b) vertical velocity component (red; unit in $\mathrm{m} \mathrm{s}^{-1}$; left $y$ axis) and potential temperature (blue; unit in K; right $y$ axis); (c) perturbation of hydrostatic pressure correction (red; unit in hPa; left $y$ axis), static pressure (blue; unit in $\mathrm{hPa}$; right $y$ axis) and corrected static pressure (black; unit in hPa; left $y$ axis); and (d) flight height (red; unit in $\mathrm{km}$; left $y$ axis) and terrain (blue; black shading below terrain; unit in km; right $y$ axis). The series in segments J3 and M2 are reversed to facilitate the comparison with $\mathrm{J} 1+\mathrm{J} 2$ and $\mathrm{M} 1$, respectively. Therefore, the orientation of the $x$ axis is from west to east along each flight segment. The distance between minor tick marks in the $x$ axis is $100 \mathrm{~km}$. The perturbations in (c) are defined as the differences between the original data and their mean from their corresponding segments.

where $z$ is the GPS altitude, $z_{\text {ref }}$ is the average altitude of flight segment and $\bar{\rho}$ is the average density of flight segment. Corrected static pressure $p_{\mathrm{c}}$ from Eq. (1) is to correct the measured static pressure $p_{\mathrm{s}}$ to a common height level (i.e., $z_{\text {ref }}$ ) based on the assumption of local hydrostatic balance. Smith et al. (2008) suggest that the contribution of $p_{\mathrm{s}}$ to $p_{\mathrm{c}}$ is much smaller than $p_{\mathrm{h}}$, because it is assumed that the aircraft almost flies on an isobaric surface.

Consistent with what was predicted by the real-time WRF forecast guidance (as shown in Fig. 11 of Pan et al., 2010) as well as simulated by the high-resolution post-mission WRF simulations (in particular the horizontal divergence as potential signals of gravity waves as shown in Fig. 2), the GV in situ measurements of different atmospheric variables suggest there are prevalent gravity wave activities along almost every leg of the $8 \mathrm{~h}$ flight, most notably in the vertical motion field. The largest amplitude of $w$ (over $2 \mathrm{~m} \mathrm{~s}^{-1}$ ) is during the middle portion of segment $\mathrm{J} 3(680-780 \mathrm{~km})$ on the lee slopes of the Rocky Mountains (also see the discussion in Sect. 5.2). The high terrain and the lee slopes also have the enhanced vertical motions for both segment M1 and segment M2. Though not as large in amplitude, enhanced fluctuations of vertical motions are also observed in the northern end of segment J3, which is in the exit region of the upper-level jet streak and above the surface front. The enhanced variances of vertical motion, accompanied by the changes in horizontal wind and potential temperature, may be associated with topography for both M1 and M2 segments, even though the role of the jet cannot be isolated.

Power spectra of five selected aircraft measurement variables are given in Fig. 4 for each of the five flight segments during RF02. The calculations of the spectra are performed with the "specx_anal" function in the NCAR Command Language (NCL). Several steps are done before the calculations. 


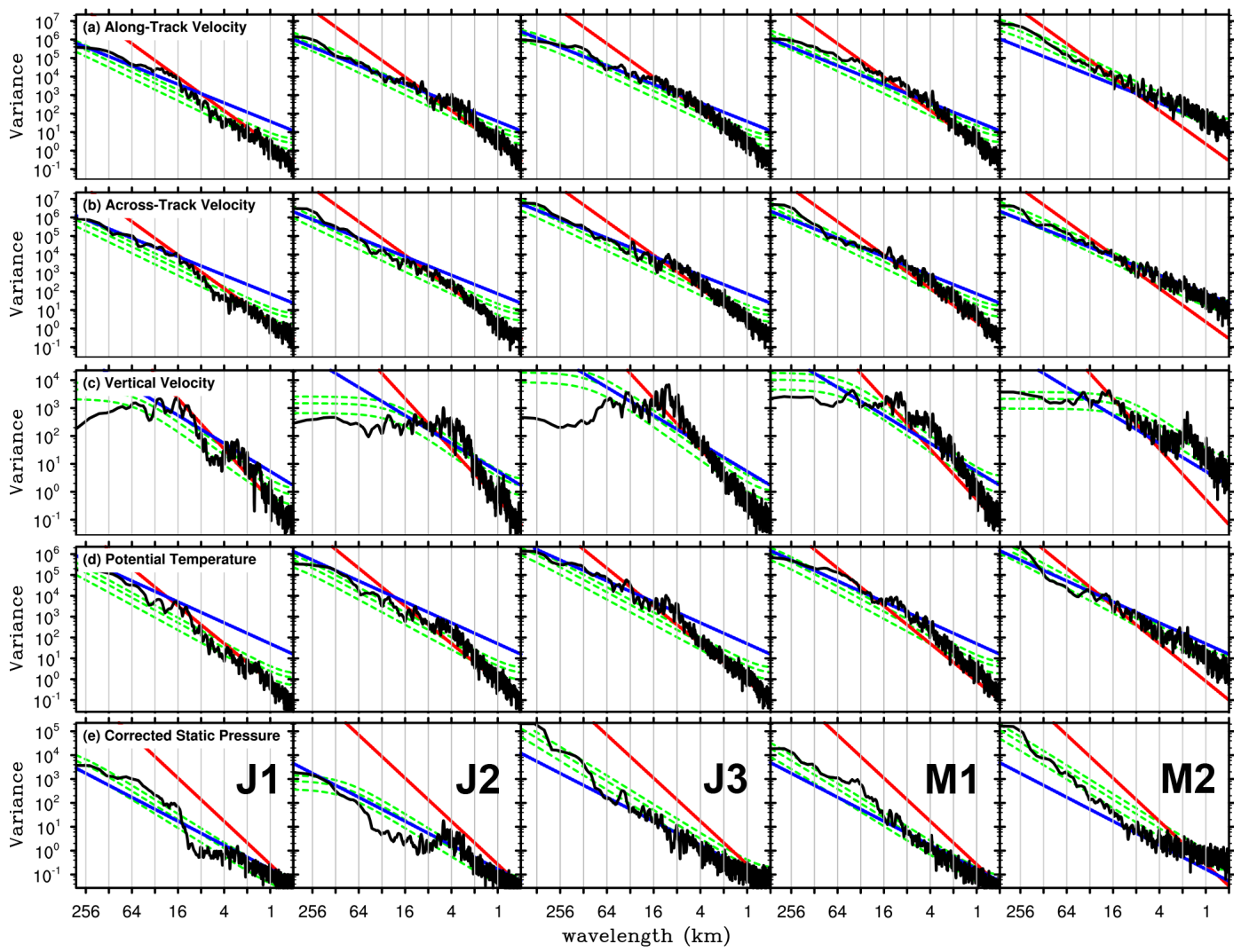

Figure 4. The spectrum (black line) of GV flight-level aircraft measurement during five selected segments (from left to right: J1, J2, J3, M1 and M2) of RF02 in START08: (a) along-track velocity component (unit in $\mathrm{m}^{2} \mathrm{~s}^{-2} \times \mathrm{m}$ ), (b) across-track velocity component (unit in $\mathrm{m}^{2} \mathrm{~s}^{-2} \times \mathrm{m}$ ), (c) vertical velocity component (unit in $\mathrm{m}^{2} \mathrm{~s}^{-2} \times \mathrm{m}$ ), (d) potential temperature (unit in $\mathrm{K}^{2} \times \mathrm{m}$ ), and (e) corrected static pressure (unit in $\mathrm{hPa}^{2} \times \mathrm{m}$ ). Green lines show the theoretical Markov spectrum and the 5 and $95 \%$ confidence curves using the lag 1 autocorrelation. The blue (red) reference lines have slopes of $-5 / 3(-3)$.

Firstly, the mean and least squares linear trend in each of the series are removed. Secondly, smoothing by averaging seven periodogram estimates is performed. Thirdly, $10 \%$ of the series are tapered. For segment $\mathrm{J} 1, u, v, \theta$ and $p_{\mathrm{c}}$ have several significant spectral peaks for wavelengths ranging from 16 to $128 \mathrm{~km}$ (mesoscale). The statistically significant spectral peaks in $w$ are more for smaller scales, one at 2$4 \mathrm{~km}$, and the other at $8-32 \mathrm{~km}$. The spectral characteristics for segment $\mathrm{J} 2$ are mostly the same as for $\mathrm{J} 1$ except for much less power at longer wavelengths (16-128 km) and only one peak at smaller scales $(2-8 \mathrm{~km})$. For segment $\mathrm{J} 3$, both $u$ and $\theta$ have statistically significant spectral peaks at mesoscales $(\sim 50$ and $128 \mathrm{~km})$ and at smaller scales $(8-16 \mathrm{~km})$, the later of which is also very pronounced for the $w$ spectrum. No significant spectral peak is found for the corrected static pressure $p_{\mathrm{c}}$ for segment $\mathrm{J} 3$, except at $512 \mathrm{~km}$, which is likely a reflection of the subsynoptic-scale pressure patterns at the flight level (Fig. 2d). For segment M1, there is a significant mesoscale spectral peak at around 32-64 km for $u, \theta$ and $p_{\mathrm{c}}$, while smaller-scale variations from 4 to $16 \mathrm{~km}$ are also significant for nearly all variables except for $p_{\mathrm{c}}$. There are al- most no significant spectral peaks for all five variables for segment M2 except for around $2 \mathrm{~km}$ for $w$.

Past studies from both aircraft observations (e.g., Nastrom and Gage, 1985; Bacmeister et al., 1996; Lindborg, 1999) and numerical simulations (e.g., Skamarock, 2004; Waite and Snyder, 2013) have revealed/verified the existence of an approximate $-5 / 3$ power law that is expected for the direct energy cascade in isotropic three-dimensional turbulence (e.g., Kolmogorov, 1941) and the inverse cascade in two dimensions (e.g., Kraichnan, 1967), as well as an approximate -3 power law that is expected for quasigeostrophic turbulence theory (e.g., Charney, 1971). The spectral slopes of different variables derived from the flight-level measurements from START08 are thus examined here in detail. Overall in segment J3, the spectrum slope for $\theta$ (the third column in Fig. 4d) is remarkably similar to those for $u$ (the third column in Fig. 4a) and $v$ (the third column in Fig. 4b), except that there appears to be a deviation from both -3 and $-5 / 3$ power laws for scales of $\sim 8-\sim 16 \mathrm{~km}$. The spectral slope of $w$ (the third column in Fig. 4c) is also similar to that of $\theta$ (the third column in Fig. 4d) for all scales below $32 \mathrm{~km}$, in- 

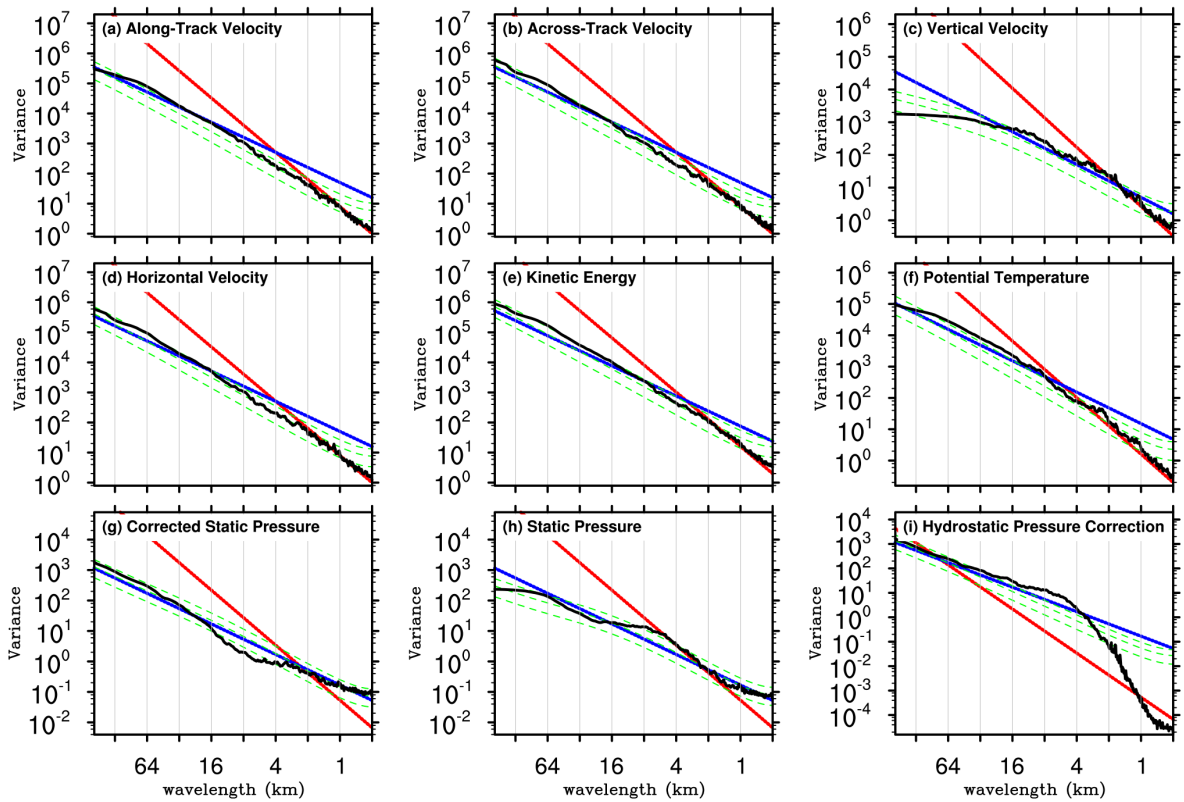

Figure 5. Composite spectrum (black line) of GV flight-level aircraft measurement averaging over all 68 segments in START08 (colored lines in Fig. 1): (a) along-track velocity component (unit in $\left.\mathrm{m}^{2} \mathrm{~s}^{-2} \times \mathrm{m}\right),(\mathbf{b})$ across-track velocity component (unit in $\left.\mathrm{m}^{2} \mathrm{~s}-2 \times \mathrm{m}\right)$, (c) vertical velocity component (unit in $\mathrm{m}^{2} \mathrm{~s}^{-2} \times \mathrm{m}$ ), (d) horizontal velocity component (unit in $\mathrm{m}^{2} \mathrm{~s}^{-2} \times \mathrm{m}$ ), (f) potential temperature (unit in $\mathrm{K}^{2} \times \mathrm{m}$ ), (g) corrected static pressure (unit in $\mathrm{hPa}^{2} \times \mathrm{m}$ ), (h) static pressure (unit in $\mathrm{hPa}^{2} \times \mathrm{m}$ ), and (i) hydrostatic pressure correction $\left(\right.$ unit in $\mathrm{hPa}{ }^{2} \times \mathrm{m}$ ) The subplot (e) kinetic energy (unit in $\mathrm{m}^{2} \mathrm{~s}^{-2} \times \mathrm{m}$ ) is the sum of (a)-(c). Green lines show the composite curves of the theoretical Markov spectrum and the 5 and $95 \%$ confidence curves using the lag 1 autocorrelation. The blue (red) reference lines have slopes of $-5 / 3(-3)$.

cluding the abovementioned deviation. However, for scales larger than $\sim 32 \mathrm{~km}$, the slope of $w$ (the third column in Fig. 4c) quickly dropped to almost zero, which is consistent with the continuity equation for near-balanced non-divergent large-scale motions.

There are also similarities and differences in spectral slopes among different flight segments depicted in Fig. 4. For example, the abovementioned spectral shapes of $u$ and $v$ from segment $\mathrm{J} 3$ are similar to those from segment $\mathrm{J} 2$ (i.e., the second and third columns in Fig. 4a and b). Such consistent signals probably result from sampling under similar large-scale background flow at similar flight altitude with almost identical topography, especially between the adjacent flight segments $\mathbf{J} 1+\mathrm{J} 2$ and $\mathrm{J} 3$. Despite the overall resemblance among the flight segments of RF02, there are some unique characteristics in the power spectral distributions for individual segments. For segments M1 and M2, for example, (i.e., the fourth column vs. the fifth column in Fig. 4), the slopes of $u$ and $v$ during segment M1 are approximately consistent with a -3 power law for the scale of $\sim 0.5-\sim 8 \mathrm{~km}$, while those during segment M2 follows a $-5 / 3$ power law instead. This is probably associated with the fact that segment M2 successfully captures a rapid decrease in $u$ (from $\sim 65$ to $\sim 40 \mathrm{~m} \mathrm{~s}^{-1}$ ) while segment M1 has no such a dramatic reduction in $u$ (the fourth column in Fig. 3a vs. the fifth column in Fig. 3a). Note that the aircraft during segment M1 flew away from the jet core region, as the jet was still moving eastward to the downhill side of the topography. In contrast, the aircraft during segment M2 flew directly toward the approaching jet core at a lower flight level than segment M1 (the fourth column in Fig. 3d vs. the fifth column in Fig. 3d), and the observed decline of $u$ (i.e., a potential jet exit region) is located roughly on the downhill side of the topography (the fifth column in Fig. 3d). This suggests that the spectral slopes for the aircraft measurements can, in fact, be extremely sensitive to changes in the background flow, even though sampling takes place in the same area only a few hours apart.

Figure 5 shows composite spectra for eight selected variables averaged over 68 flight segments. Unsurprisingly, the composite spectra are much smoother due to averaging. For $u$ (Fig. 5a), $v$ (Fig. 5b), and horizontal wind speed $V$ (Fig. 5d), the slope of the power spectra are consistent with a $-5 / 3$ power law for scales above $\sim 8-\sim 16 \mathrm{~km}$. For $w$ (Fig. $5 \mathrm{c}$ ), its spectral slope is generally consistent with -3 power laws for the scale of $\sim 0.5-\sim 2 \mathrm{~km}$ but is nearly zero for scales over $32 \mathrm{~km}$, while the slopes in between $(\sim 2-\sim 32 \mathrm{~km})$ appear to follow an approximate $-5 / 3$ power law, with a statistically significant spectral peak at $\sim 8-16 \mathrm{~km}$. Even though the kinetic energy spectra (Fig. 5e) may show a $-5 / 3$ slope that covers a larger range, the -3 slope over the small scale in kinetic energy is still evident. For $\theta$ (Fig. 5f) at scales between $\sim 0.5 \mathrm{~km}$ and $\sim 2 \mathrm{~km}$, its slope also obeys a -3 power law. For $\theta$ (Fig. 5f) at the scale greater than $\sim 8-\sim 16 \mathrm{~km}$, the slope of the power spectrum tends to have a $-5 / 3$ slope, 
which is similar to $u$ (Fig. 5a), $v$ (Fig. 5b), and $V$ (Fig. 5d) for the same scales. For all the three pressure-related variables (i.e., $p_{\mathrm{c}}$ in Fig. $5 \mathrm{~g} ; p_{\mathrm{s}}$ in Fig. $5 \mathrm{~h} ; p_{\mathrm{h}}$ in Fig. 5i), their slopes generally fall around a $-5 / 3$ power law, except for scales smaller than $\sim 4 \mathrm{~km}$ in $p_{\mathrm{h}}$ (Fig. 5i). However, it is worth noting that there is a sudden concavity (convexity) in $p_{\mathrm{c}}$ ( $p_{\mathrm{s}}$ or $p_{\mathrm{h}}$ ) for scales between $\sim 4 \mathrm{~km}$ and $\sim 16 \mathrm{~km}$ (also see the discussion in Sect. 5.3).

\section{Wavelet analysis}

\subsection{Single-variable wavelet analysis}

Standard spectral analysis methods characterize the variance as a function of wavelength for an entire data record (flight segment) but do not indicate where variance of a particular wavelength is located within the data record. We use wavelet analysis to complement the spectral analysis in Sect. 3 to study the variance as a function of wavelength within the five flight segments from RF02. A Morlet wavelet function is employed in this study (e.g., Torrence and Compo, 1998; Zhang et al., 2001; Woods and Smith, 2010). This is a continuous wavelet transform that uses non-orthogonal complex wavelet functions comprising a plane wave modulated by a Gaussian function (e.g., Eq. 1 in Torrence and Compo, 1998):

$\psi_{0}(\eta)=\pi^{-1 / 4} e^{i \omega_{0} \eta} e^{-\eta^{2} / 2}$,

where $\omega_{0}$ is the dimensionless wavenumber and $\eta$ is the dimensionless distance. Here $\omega_{0}$ is set to 6 to satisfy the admissibility condition (Farge, 1992). The continuous wavelet transform, used to extract localized spectral information, is defined as the convolution of the series of interest $x$ with the complex conjugate of the wavelet (e.g., Eq. 2 in Torrence and Compo, 1998):

$W_{n}(s)=\sum_{n^{\prime}=0}^{N-1} x_{n^{\prime}} \psi^{*}\left[\frac{\left(n^{\prime}-n\right) \Delta x}{s}\right]$,

where $^{*}$ is the complex conjugate, $n$ is the localized position index, $s$ is the wavelet scale, and $\Delta x$ is the resolution of the data $(0.25 \mathrm{~km}$ in this case). The cone of influence (COI) shows the region of the wavelet spectrum where the edge errors cannot be ignored. Computation of the wavelet spectrum and edge error is performed with the wavelet function of Eq. (3) (Torrence and Compo, 1998) in NCL.

Figure 6 contains the wavelet power spectra of five selected observed variables along the five selected flight segments of RF02. Using the long segment J3 as an example again (third column in Fig. 6), there is a substantial peak in the power of $u$ (Fig. 6a) at wavelengths around $128 \mathrm{~km}$ between 400 and $700 \mathrm{~km}$ along the flight leg (also seen in $p_{\mathrm{c}}$ of Fig. $\left.6 \mathrm{e}\right) ; \sim 100 \mathrm{~km}$ wave power peaks at $100-300 \mathrm{~km}$; the wave power of wavelengths from $\sim 64$ to $\sim 128 \mathrm{~km}$ also peaks at $1200-1400 \mathrm{~km}$. The greatest similarity is between the spectra of $w$ and $\theta$ (Fig. 6c, d). For example, from 100 to $800 \mathrm{~km}$ in segment $\mathrm{J} 3$, the local maximum of power in $w$ (the third column in Fig. 6c) resembles the one in $\theta$ (the third column in Fig. 6d). In particular, three distinguished wave modes $(\sim 64, \sim 32$, and $\sim 10 \mathrm{~km}$ in along-track wavelength) collocate at $600-800 \mathrm{~km}$ (downstream of a localized hill around $600 \mathrm{~km}$ in the third column of Fig. 3d). Relatively persistent waves with $\sim 10 \mathrm{~km}$ along-track wavelength are shown at $200-700 \mathrm{~km}$ in $w$, which corresponds to a similar peak in the spectral analysis of $w$ in the third column of Fig. 4c. Note that such $\sim 10 \mathrm{~km}$ waves are also found in other flight segments in RF02 (e.g., 0-600 km during segment M1, the fourth column in Fig. 6c) and other research flights in START08 (not shown). Interpretations of such small-scale, localized wave variances, as well as mesoscale, localized wave variances, are discussed in Sect. 5.

\subsection{Polarization relationships from cross-wavelet analysis}

Following Woods and Smith (2010), the phase relationship between two variables (e.g., $u$ and $v$, hereafter in short noted as $\left.\left(u^{\prime} v^{\prime}\right)_{p}\right)$ can be determined from the cospectrum $\left(u^{\prime} v^{\prime}\right)_{c}$ and quadrature spectrum $\left(u^{\prime} v^{\prime}\right)_{q}$, which are defined as (also see Sect. 6c in Torrence and Compo, 1998; Eq. 8 and Appendix A in Woods and Smith, 2010)

$\left(u^{\prime} v^{\prime}\right)_{c}=\operatorname{Re}\left\{U_{n}\left(s_{j}\right) V_{n}^{*}\left(s_{j}\right)\right\}$,

$\left(u^{\prime} v^{\prime}\right)_{q}=\operatorname{Im}\left\{U_{n}\left(s_{j}\right) V_{n}^{*}\left(s_{j}\right)\right\}$,

where $U_{n}$ and $V_{n}$ represent the wavelet transforms of $u$ and $v$ from Eq. (3), $U_{n}\left(s_{j}\right) V_{n}^{*}\left(s_{j}\right)$ is the complex-valued crosswavelet spectrum, while $\operatorname{Re}\{\}$ and $\operatorname{Im}\{\}$ represent the real and imaginary parts of the variables inside the parentheses, respectively. Woods and Smith (2010) focus on the energy flux by analyzing $\left(p_{\mathrm{c}}^{\prime} w^{\prime}\right)_{c}$ from Eq. (4) for vertically propagating waves and $\left(p_{\mathrm{c}}^{\prime} w^{\prime}\right)_{q}$ from Eq. (5) for vertically trapped/ducted waves. In principle, $\left(p_{\mathrm{c}}^{\prime} w^{\prime}\right)_{p}$ should be, theoretically speaking, associated with $\left(u^{\prime} w^{\prime}\right)_{p}\left(\left(v^{\prime} w^{\prime}\right)_{p}\right)$ (e.g., Eliassen and Palm, 1960; Lindzen, 1990). This is particularly true for stationary mountain waves, which may be present for RF02 given complex topography during each of the flight segments. However, in practice, Woods and Smith (2010, their Sect. 7) argued that the perturbation longitudinal velocity was noisier than pressure in their study. In addition to Eqs. (4) and (5), one can also define the absolute coherence phase angle as $\frac{180}{\pi} \times \arctan \left(\left|\frac{\operatorname{Im}\left\{U_{n}\left(s_{j}\right) V_{n}^{*}\left(s_{j}\right)\right\}}{\operatorname{Re}\left\{U_{n}\left(s_{j}\right) V_{n}^{*}\left(s_{j}\right)\right\}}\right|\right)$ ) (also see Sect. 6d in Torrence and Compo, 1998).

The phase relations among multiple variables are examined to further explore whether the enhanced variances from the spectral and wavelet analyses are vertically propagating gravity waves. Figure 7 shows three selected examples of cospectrum analysis (i.e., $\left(u^{\prime} w^{\prime}\right)_{c}$ in Fig. 7a, $\left(v^{\prime} w^{\prime}\right)_{c}$ in Fig. $7 \mathrm{~b},\left(p_{\mathrm{c}}^{\prime} w^{\prime}\right)_{c}$ in Fig. 7c), one selected example of 

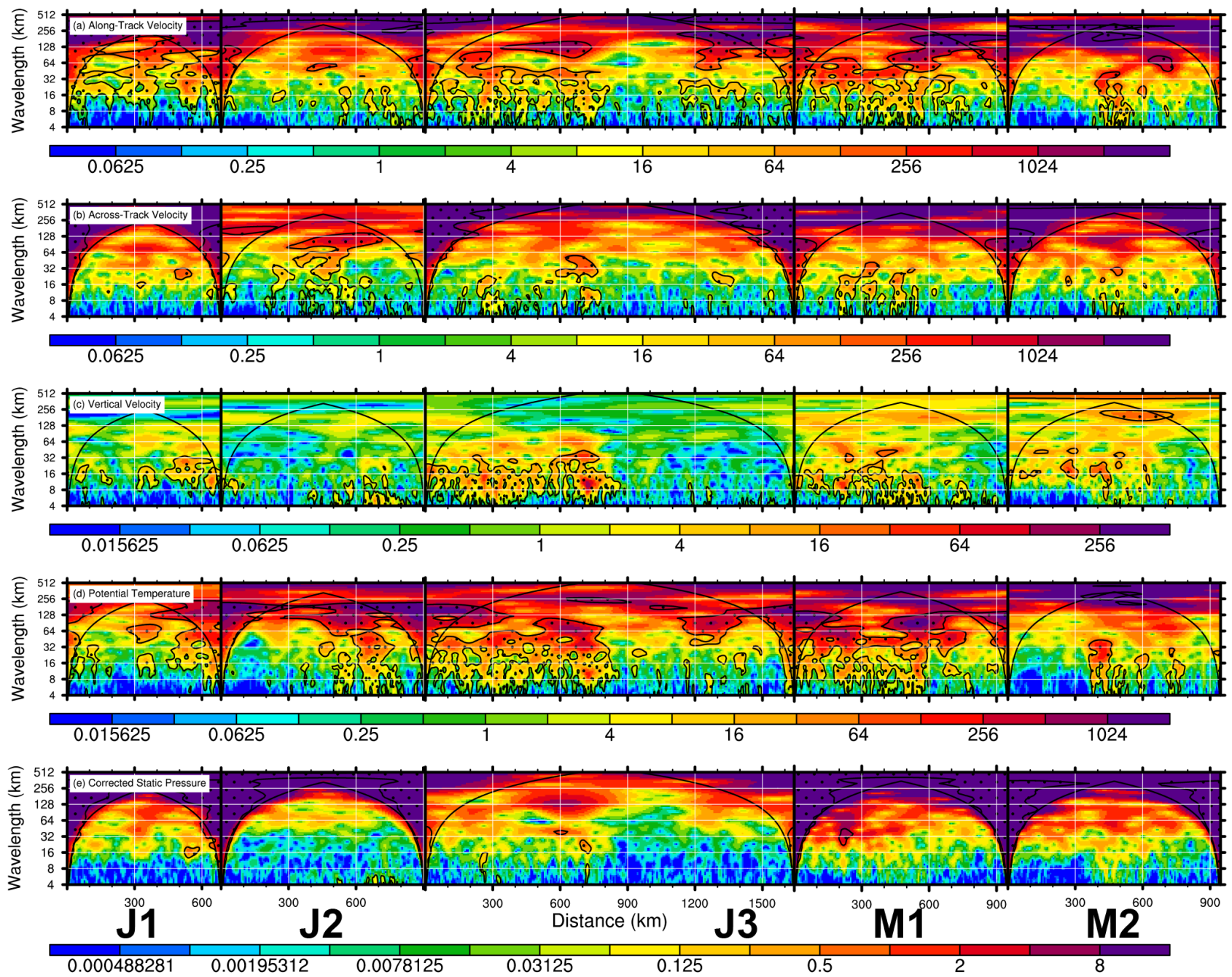

Figure 6. Wavelet power spectrum of GV flight-level aircraft measurement during five selected segments (from left to right: J1, J2, J3, M1 and M2) of RF02 in START08: (a) along-track velocity component, (b) across-track velocity component, (c) vertical velocity component, (d) potential temperature, and (e) corrected static pressure. Reference line (black line) shows the cone of influence (COI), and the area outside COI is where edge error becomes important. Black contour lines with dot shading represent $95 \%$ significance level based on a red noise background (also see Torrence and Compo, 1998; Woods and Smith, 2010). The $x$ axis is the same as in Fig. 3, including the reversal of segment $\mathrm{J} 3$ and $\mathrm{M} 2$.

quadrature spectrum analysis (i.e., $\left(\theta^{\prime} w^{\prime}\right)_{q}$ in Fig. 7d), and one example of absolute coherence phase angle for $\left(\theta^{\prime} w^{\prime}\right)_{p}$ (Fig. 7e). In the case of a single monochromatic internal gravity wave propagating vertically, for $\left(u^{\prime} w^{\prime}\right)_{c}$ (Fig. 7a), positive (negative) values indicate upward (downward) flux of along-track momentum. For $\left(v^{\prime} w^{\prime}\right)_{c}$ (Fig. 7b), positive (negative) values indicate upward (downward) flux of acrosstrack momentum. For $\left(p_{\mathrm{c}}^{\prime} w^{\prime}\right)_{c}$ (Fig. 7c), positive (negative) values indicate positive (negative) vertical energy transport. For the quadrature spectrum of $\left(\theta^{\prime} w^{\prime}\right)_{q}$ (Fig. 7d), values should be nonzero while the absolute coherence phase angle of $\left(\theta^{\prime} w^{\prime}\right)_{p}$ (Fig. 7e) should be close to $90^{\circ}$.

We again take segment $\mathrm{J} 3$ as an example (the third column in Fig. 7): for the small-scale component with along-track wavelength smaller than $50 \mathrm{~km}$ (horizontal solid line), enhanced but incoherent variances are detected at $100-500 \mathrm{~km}$ and at $600-800 \mathrm{~km}$, with fluctuating positive and negative values for both $\left(u^{\prime} w^{\prime}\right)_{c}$ (the third column in Fig. 7a) and $\left(v^{\prime} w^{\prime}\right)_{c}$ (the third column in Fig. 7b). The variations in the signs of vertical transports of horizontal momentum fluxes imply that this flight segment is sampling waves propagating in both forward and backward directions, assuming the vertical energy transports are generally upward. Correspondingly, the absolute coherence phase angle for $\left(u^{\prime} v^{\prime}\right)_{p}$ (not shown) also alternates frequently between nearly $0^{\circ}$ and nearly $90^{\circ}$. In particular, some of the enhanced variances in the cospectra for along-track wavelengths from $\sim 4$ to $\sim 16 \mathrm{~km}$, though 

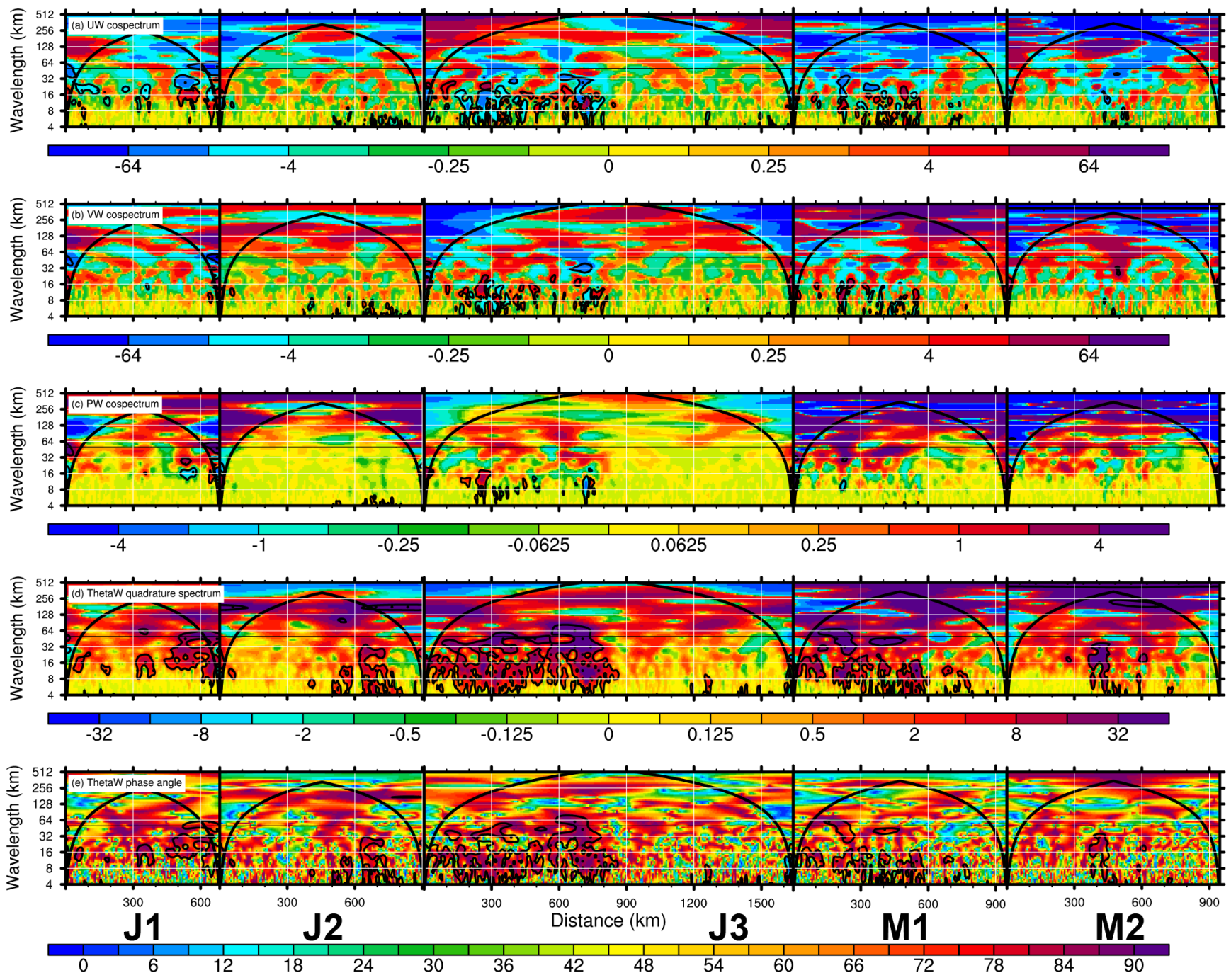

Figure 7. The wavelet cospectrum of (a) $\left(u^{\prime} w^{\prime}\right)_{c}$, (b) $\left(v^{\prime} w^{\prime}\right)_{c}$, (c) $\left(p_{\mathrm{c}}^{\prime} w^{\prime}\right)_{c}$, (d) the quadrature spectrum of $\left(\theta^{\prime} w^{\prime}\right)_{q}$, and (e) the absolute coherence phase angle of $\left(\theta^{\prime} w^{\prime}\right)_{p}$ for GV flight-level aircraft measurements during five selected segments (from left to right: J1, J2, J3, M1 and M2) of RF02 in START08. Reference line (black line) shows the COI, and the area outside COI is where edge error becomes important. Black contour lines with dot shading represent $95 \%$ significance level (also see Torrence and Compo, 1998, and Woods and Smith, 2010). The $x$ axis is the same as in Fig. 3, including the reversal of segment J3 and M2. The horizontal black line marks the scale of $50 \mathrm{~km}$.

fluctuating in signs, are significant above the $95 \%$ confidence level.

For the mesoscale component with wavelengths from $\sim 50$ to $\sim 100 \mathrm{~km}$, remarkable localized quadrature variance is found in $\left(\theta^{\prime} w^{\prime}\right)_{q}$ (the third column in Fig. 7d) at 500-800 km, consistent with the wavelet analysis of $w$ in the third column of Fig. $6 \mathrm{c}$ and $\theta$ in the third column of Fig. 6d. The absolute coherence phase angle for $\left(\theta^{\prime} w^{\prime}\right)_{p}$ in Fig. 7e also demonstrates that the cross-wavelet spectrum between $\theta$ and $w$ is mostly dominated by their quadrature spectrum (red color shading in Fig. 7e), though there are some exceptions (blue color shading in Fig. 7e).
The similarities/discrepancies among different wavelet cospectra and quadrature spectra examined in Fig. 7 demonstrate the difficulties in gravity wave identification and the uncertainties in gravity wave characteristics estimation based solely on aircraft measurements.

In addition to cross-wavelet analysis, the signs of the net fluxes (e.g., $\overline{u^{\prime} w^{\prime}}, \overline{v^{\prime} w^{\prime}}$, and $\overline{w^{\prime} p_{c}^{\prime}}$ ) at each wavelength can also be estimated by the cospectrum analysis based on Fourier transform over the entire segment (not shown). Generally speaking, for the scale below $\sim 32 \mathrm{~km}$, both positive values and negative values are important in $\overline{u^{\prime} w^{\prime}}$ and $\overline{v^{\prime} w^{\prime}}$, while positive $\overline{w^{\prime} p_{\mathrm{c}}^{\prime}}$ appears to be more continuous than negative $\overline{w^{\prime} p_{\mathrm{c}}^{\prime}}$. For the scale above $\sim 32 \mathrm{~km}$, negative $\overline{u^{\prime} w^{\prime}}$ (pos- 
Segment J3 (distance: 250-360km; bandpass window: 100-120km)
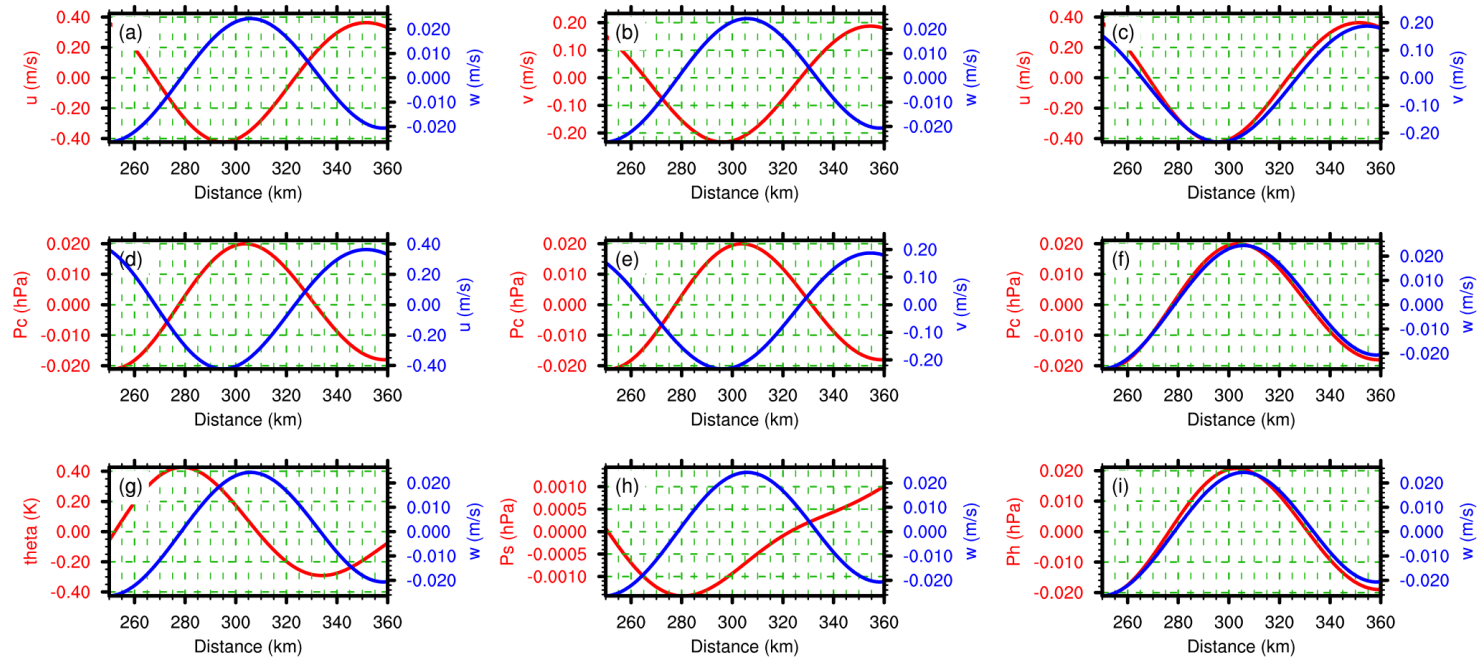

Figure 8. A relatively good/clean example of mesoscale variations during segment J3 (250-360 km): (a) along-track velocity component (red; unit in $\mathrm{m} \mathrm{s}^{-1}$ ) and vertical velocity component (blue; unit in $\mathrm{m} \mathrm{s}^{-1}$ ), (b) across-track velocity component (red; unit in $\mathrm{m} \mathrm{s}^{-1}$ ) and vertical velocity component (blue; unit in $\mathrm{m} \mathrm{s}^{-1}$ ), (c) along-track velocity component (red; unit in $\mathrm{m} \mathrm{s}^{-1}$ ) and across-track velocity component (blue; unit in $\mathrm{m} \mathrm{s}^{-1}$ ), (d) corrected static pressure (red; unit in $\mathrm{hPa}$ ) and along-track velocity component (blue; unit in $\mathrm{m} \mathrm{s}^{-1}$ ), (e) corrected static pressure (red; unit in $\mathrm{hPa}$ ) and across-track velocity component (blue; unit in $\mathrm{m} \mathrm{s}^{-1}$ ), (f) corrected static pressure (red; unit in hPa) and vertical velocity component (blue; unit in $\left.\mathrm{m} \mathrm{s}^{-1}\right)$, (g) potential temperature (red; unit in $\mathrm{K}$ ) and vertical velocity component (blue; unit in $\mathrm{m} \mathrm{s}^{-1}$ ), (h) static pressure (red; unit in $\mathrm{hPa}$ ) and vertical velocity component (blue; unit in $\mathrm{m} \mathrm{s}^{-1}$ ), and (i) hydrostatic pressure correction (red; unit in $\mathrm{hPa}$ ) and vertical velocity component (blue; unit in $\mathrm{m} \mathrm{s}^{-1}$ ). A wavelet-based bandpass filter is applied to extract signals with wavelengths from 100 to $120 \mathrm{~km}$ for all the above flight variables.

itive $\left.\overline{w^{\prime} p_{\mathrm{c}}^{\prime}}\right)$ appears to be more continuous than positive $\overline{u^{\prime} w^{\prime}}$ (negative $\overline{w^{\prime} p_{\mathrm{c}}^{\prime}}$ ), while there is no dominant sign for $\overline{v^{\prime} w^{\prime}}$ one way or the other.

\section{Selected wave-like examples: signal of gravity waves or measurement noise?}

This section examines several examples of wave-like variations during segment $\mathrm{J} 3$ in more detail. Bandpass-filtered values of selected variables are computed by synthesizing the wavelet transform using wavelets with scales between $j_{1}$ and $j_{2}$ using (e.g., Eq. 29 in Torrence and Compo, 1998)

$x_{n}^{\prime}=\frac{\Delta j \Delta x^{1 / 2}}{C_{\delta} \psi_{0}(0)} \sum_{j=j_{1}}^{j_{2}} \frac{\operatorname{Re}\left\{W_{n}\left(s_{j}\right)\right\}}{s_{j}^{1 / 2}}$,

where $\Delta j$ is the scale resolution and $C_{\delta}$ is a reconstruction factor taken as 0.776 for Morlet wavelets. The waveletbased filter in Eq. (6) has the advantage in removing noise at each wavenumber and isolating single events with a broad power spectrum or multiple events with different wavenumber (Donoho and Johnstone, 1994; Torrence and Compo, 1998).

Nine pairs of variables, including $\left(u^{\prime} w^{\prime}\right)_{p},\left(v^{\prime} w^{\prime}\right)_{p}$, $\left(u^{\prime} v^{\prime}\right)_{p},\left(p_{\mathrm{c}}^{\prime} u^{\prime}\right)_{p},\left(p_{\mathrm{c}}^{\prime} v^{\prime}\right)_{p},\left(p_{\mathrm{c}}^{\prime} w^{\prime}\right)_{p},\left(\theta^{\prime} w^{\prime}\right)_{p},\left(p_{\mathrm{s}}^{\prime} w^{\prime}\right)_{p}$, and $\left(p_{\mathrm{h}}^{\prime} w^{\prime}\right)_{p}$, are selected to examine whether the phase relationship of the variations in the airborne measurements is consistent with the linear theory for gravity waves. Generally speaking, the phase relation between two variables can be classified into two major categories: (1) in-phase or out-ofphase relationships, in which one variable leads or lags the other variable by approximately 0 or $180^{\circ}$; and (2) quadrature relationships, in which one variable leads or lags the other by approximately $90^{\circ}$.

The phase relationships for linear gravity waves are determined by theory and their propagation characteristics. Take $\left(u^{\prime} w^{\prime}\right)_{p},\left(v^{\prime} w^{\prime}\right)_{p}$, and $\left(p_{\mathrm{c}}^{\prime} w^{\prime}\right)_{p}$ as examples, if they have an in- or out-of-phase relationship, the waves are propagating in the vertical direction; if they have a quadrature relationship, the waves do not propagate vertically and may be trapped or ducted. Take $\left(u^{\prime} v^{\prime}\right)_{p}$ as another example, if they have an in- or out-of-phase relationship, the waves may be internal gravity waves whose intrinsic frequencies are much higher than the Coriolis frequency; if they have a quadrature relationship, the waves may be inertio-gravity waves with intrinsic frequencies close to the Coriolis frequency. For vertically propagating linear gravity waves, $\left(\theta^{\prime} w^{\prime}\right)_{p}$ should have a quadrature relationship. According to Smith et al. (2008), $p_{\mathrm{h}}^{\prime}$ should dominate over $p_{\mathrm{s}}^{\prime}$, if the aircraft almost flies on a 
Segment J3 (distance: 560-688km; bandpass window: 118-138km)
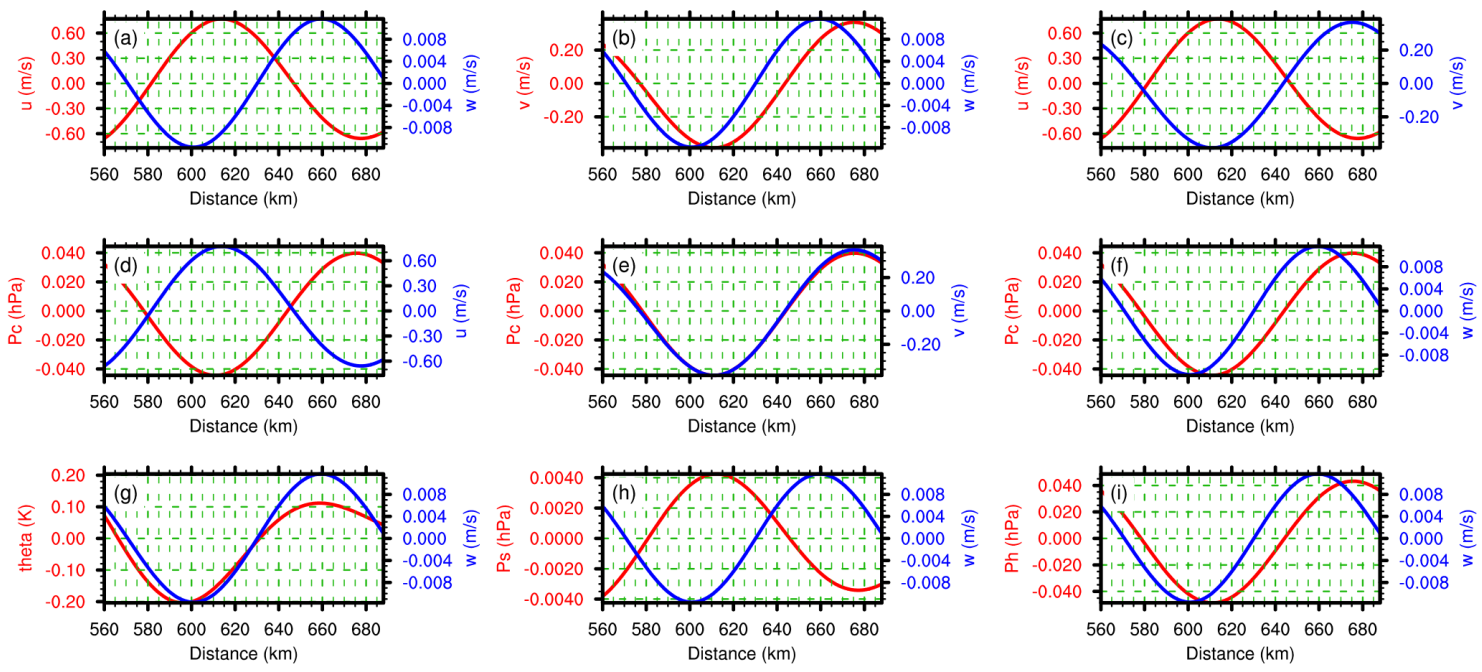

Figure 9. Same as in Fig. 8, but for a relatively bad/noisy example of mesoscale variations during segment J3 (560-688 km). The waveletbased bandpass window is $118-138 \mathrm{~km}$.

constant pressure surface. Consequently, $\left(p_{\mathrm{h}}^{\prime} w^{\prime}\right)_{p}$ should be almost identical to $\left(p_{\mathrm{c}}^{\prime} w^{\prime}\right)_{p}$.

\subsection{Examples of mesoscale wave variances}

Figure 8 demonstrates an example of potential mesoscale gravity waves selected based on the wavelet analysis of $u$ (Fig. 6a), $w$ (Fig. 6c), $\theta$ (Fig. 6d), and $p_{\mathrm{c}}$ (Fig. 6e) at 250$360 \mathrm{~km}$ in segment $\mathrm{J} 3$ (the exit region of the northwesterly jet in Fig. 2d). The wave signals are further highlighted by applying a wavelet-based filter (i.e., Eq. 6) to extract wavelike variations with along-track wavelength between 100 and $120 \mathrm{~km}$. Panels a, b, d, and e show out-of-phase relationships for $\left(u^{\prime} w^{\prime}\right)_{p},\left(v^{\prime} w^{\prime}\right)_{p},\left(p_{\mathrm{c}}^{\prime} u^{\prime}\right)_{p}$, and $\left(p_{\mathrm{c}}^{\prime} v^{\prime}\right)_{p}$, respectively; while panels c, $\mathrm{f}$, and i show in-phase relationships for $\left(u^{\prime} v^{\prime}\right)_{p},\left(p_{\mathrm{c}}^{\prime} w^{\prime}\right)_{p}$, and $\left(p_{\mathrm{h}}^{\prime} w^{\prime}\right)_{p}$. Panels g and h show quadrature relationships for $\left(\theta^{\prime} w^{\prime}\right)_{p}$ and $\left(p_{\mathrm{s}}^{\prime} w^{\prime}\right)_{p}$. The observed phase relations shown in Fig. 8 are generally consistent with linear theory for propagating monochromatic gravity waves, as indicated by the cospectrum/quadrature spectrum analysis in Fig. 7. These signals are likely to be internal gravity waves (due to the in-phase relation of $\left(u^{\prime} v^{\prime}\right)_{p}$ in Fig. 8c) with positive vertical group velocity (due to their positive vertical energy flux, Fig. 8f).

In contrast, Fig. 9 is an example of wave-like disturbances that lacks a clear, propagating, linear-wave, phase relationship. This example is also selected based on the wavelet analysis of segment $\mathrm{J} 3$ for $u, v$, and $p_{\mathrm{c}}$ (Fig. 6a, $\mathrm{b}$, and e) for along-track wavelength near $128 \mathrm{~km}$ and between 560 and $688 \mathrm{~km}$ along the segment. This segment lies above the complex topography as depicted in the third column of Fig. 3d. According to Fig. 9a-e, $\left(u^{\prime} w^{\prime}\right)_{p},\left(u^{\prime} v^{\prime}\right)_{p}$, and $\left(p_{\mathrm{c}}^{\prime} u^{\prime}\right)_{p}$ seem to have out-of-phase relationships, while $\left(v^{\prime} w^{\prime}\right)_{p}$ and $\left(p_{\mathrm{c}}^{\prime} v^{\prime}\right)_{p}$ have almost perfect in-phase relationships. These phase relationships appear to be reasonable and generally consistent with the linear theory. The near in-phase relationship exhibited by $\left(\theta^{\prime} w^{\prime}\right)_{p}$ (Fig. 9g), however, raises doubts about whether these variations are true gravity waves, as this is not consistent with linear theory. If they are in fact gravity wave signals, the discrepancy highlights the difficulties of extracting gravity wave perturbations from observations. For example, the mesoscale variances may be contaminated by small-scale variability of $\theta$ and $w$ due to the coexistence of wave variances at different scales for this region (see the wavelet analysis of $w$ in Fig. 6c in and $\theta$ in Fig. 6d). Additionally, there are uncertainties in extracting mesoscale gravity waves from a varying background flow (e.g., Zhang et al., 2004), especially for $u, v$ and $\theta$. Note that $\theta$ and $w$ have a very consistent quadrature relation from $\sim 8$ to $\sim 64 \mathrm{~km}$ for this region in their quadrature spectrum of Fig. $7 \mathrm{~d}$ (also see Fig. 7e), but this quadrature relation (the third column in Fig. 7d), including their corresponding wavelet spectrum (the third column in Fig. 6c and d), is much weaker for wavelengths near $128 \mathrm{~km}$ at $560-688 \mathrm{~km}$ in segment J3.

Consistent with Smith et al. (2008), the amplitude of $p_{\mathrm{h}}^{\prime}$ is much larger than the amplitude of $p_{\mathrm{s}}^{\prime}$ for both examples of mesoscale wave variances. Therefore, $\left(p_{\mathrm{h}}^{\prime} w^{\prime}\right)_{p}$ is almost identical to $\left(p_{\mathrm{c}}^{\prime} w^{\prime}\right)_{p}$ for both cases (Fig. 8f vs. Fig. 8i; Fig. 9f vs. Fig. 9i). It appears that the assumption of constant $p_{\mathrm{s}}$ flight height is valid for these two mesoscale examples. 
Segment J3 (distance: 650-750km; bandpass window: 32-64km)
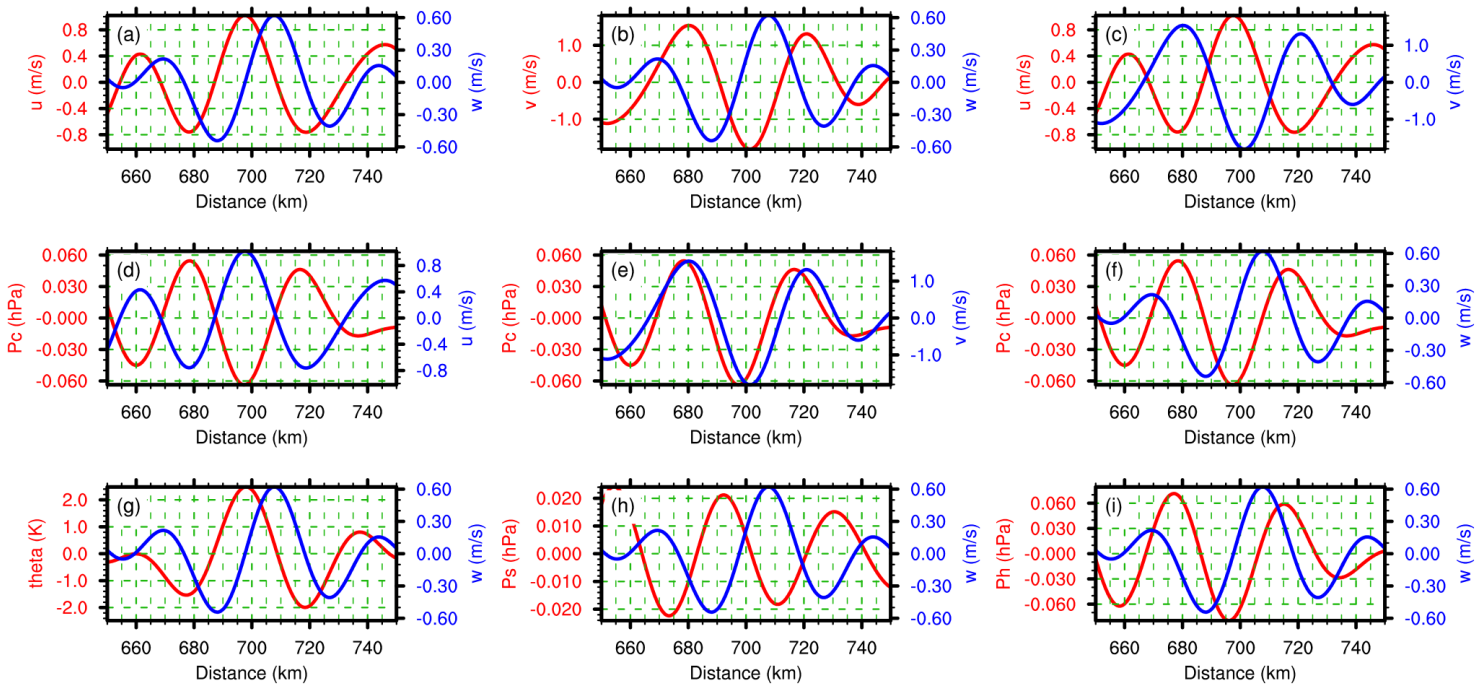

Figure 10. Same as in Fig. 8, but for a relatively good/clean example of smaller-scale variations during segment $\mathrm{J} 3$ (650-750 km). The wavelet-based bandpass window is $32-64 \mathrm{~km}$.

\subsection{Examples of small-scale wave-like variations}

Figure 10 shows an example of short-scale wave-like disturbances that have a phase relationship consistent with linear gravity wave theory based on the wavelet analysis in Fig. 6 with scales from 32 to $64 \mathrm{~km}$ located at $650-750 \mathrm{~km}$ during segment J3. In-phase relationships are seen in the filtered signals of $\left(p_{\mathrm{c}}^{\prime} v^{\prime}\right)_{p}$ (Fig. 10e), while out-of-phase relationships are seen in $\left(u^{\prime} v^{\prime}\right)_{p}$ and $\left(p_{\mathrm{c}}^{\prime} u^{\prime}\right)_{p}$ (Fig. 10c, d). Quadrature relationships can generally be seen in $\left(u^{\prime} w^{\prime}\right)_{p},\left(v^{\prime} w^{\prime}\right)_{p}$, $\left(p_{\mathrm{c}}^{\prime} w^{\prime}\right)_{p}$, and $\left(\theta^{\prime} w^{\prime}\right)_{p}$ (Fig. 10a, b, f, g). These small-scale waves have no apparent vertical flux of horizontal momentum (Fig. 10a, b) and no vertical energy flux (Fig. 10f), a key sign of vertically trapped gravity waves. Short-scale waves based on GV aircraft measurements and/or numerical simulations are also discussed in Smith et al. (2008) and Woods and Smith $(2010,2011)$.

However, parts of the small-scale wave variations derived from the in situ measurements, especially for wavelengths from 5 to $15 \mathrm{~km}$, may be difficult to classify as gravity waves. Figure 11 shows an example of short-scale wave variations in the aircraft measurements with along-track wavelengths from 8 to $16 \mathrm{~km}$ at $680-780 \mathrm{~km}$ along segment $\mathrm{J} 3$. As depicted in Fig. 11, $\left(u^{\prime} w^{\prime}\right)_{p}$ (Fig. 11a) appears to have a quadrature relationship, even though this relative phase varies, especially from 710 to $730 \mathrm{~km}$. Compared to $\left(u^{\prime} w^{\prime}\right)_{p}$ (Fig. 11a), $\left(v^{\prime} w^{\prime}\right)_{p}$ and $\left(\theta^{\prime} w^{\prime}\right)_{p}$ (Fig. 11b, g) have consistent quadrature relationships within this $100 \mathrm{~km}$ distance. On the other hand, $\left(u^{\prime} v^{\prime}\right)_{p}$ (Fig. 11c) varies significantly from one wavelength to the next. The amplitude of $w^{\prime}$ in this example is extremely large $\left(\sim 2.5 \mathrm{~m} \mathrm{~s}^{-1}\right.$ at its maximum $)$ in this selected example. In comparison, the amplitude of $p_{\mathrm{c}}^{\prime}$ is rather small, and it is actually too small to be noticed when using a wider bandpass window (not shown). Also, the quadrature relationship in $\left(p_{\mathrm{c}}^{\prime} w^{\prime}\right)_{p}$ (Fig. 11f) is not as remarkable as those in $\left(u^{\prime} w^{\prime}\right)_{p}$ and $\left(v^{\prime} w^{\prime}\right)_{p}$ (Fig. 11a, b), which appears to contradict the theoretical description of Eliassen and Palm (1960) on energy and momentum fluxes (also see Lindzen, 1990). In addition, it is worth mentioning that $\left(p_{\mathrm{s}}^{\prime} w^{\prime}\right)_{p}$ and $\left(p_{\mathrm{h}}^{\prime} w^{\prime}\right)_{p}$ in Fig. 11h and $\mathrm{i}$ have almost perfect out-of-phase and in-phase relationships, respectively.

In contradiction to Smith et al. (2008), the amplitude of $p_{\mathrm{h}}^{\prime}$ in the above example of Fig. 11 is comparable with the amplitude of $p_{\mathrm{s}}^{\prime}$ (Fig. 11h vs. Fig. 11i). Surprisingly, $\left(p_{\mathrm{c}}^{\prime} w^{\prime}\right)_{p}$, $\left(p_{\mathrm{s}}^{\prime} w^{\prime}\right)_{p}$, and $\left(p_{\mathrm{h}}^{\prime} w^{\prime}\right)_{p}$ are also very different from each other (compare Fig. 11f, h, and i). The signals of $p_{\mathrm{s}}^{\prime}$ and $p_{\mathrm{h}}^{\prime}$ (Fig. $11 \mathrm{~h}, \mathrm{i}$ ) are out of phase for wavelengths near $10 \mathrm{~km}$ and have comparable amplitude, which leads to nearly no such wave variances in $p_{\mathrm{c}}^{\prime}$ (Fig. 11d-f) given $p_{\mathrm{c}}^{\prime}$ is the sum of $p_{\mathrm{s}}^{\prime}$ and $p_{\mathrm{h}}^{\prime}$.

\subsection{Insight from spectral analysis of different pressure variables}

Figure 12a compares the power spectrum of three pressurerelated variables (i.e., corrected static pressure $p_{\mathrm{c}}$, static pressure $p_{\mathrm{s}}$, and hydrostatic pressure correction $p_{\mathrm{h}}$; also see Eq. 1). Using segment $\mathrm{J} 3$ as an example, for wavelengths greater than $\sim 32 \mathrm{~km}, p_{\mathrm{c}}$ is almost identical to $p_{\mathrm{h}}$; for wavelengths between $\sim 32$ and $\sim 4 \mathrm{~km}$, the variances between $p_{\mathrm{s}}$ and $p_{\mathrm{h}}$ are comparable, and the variances of $p_{\mathrm{c}}$ are noticeably smaller than those in $p_{\mathrm{s}}$ and $p_{\mathrm{h}}$; for wavelengths less 
Segment J3 (distance: 680-780km; bandpass window: 8-16km)
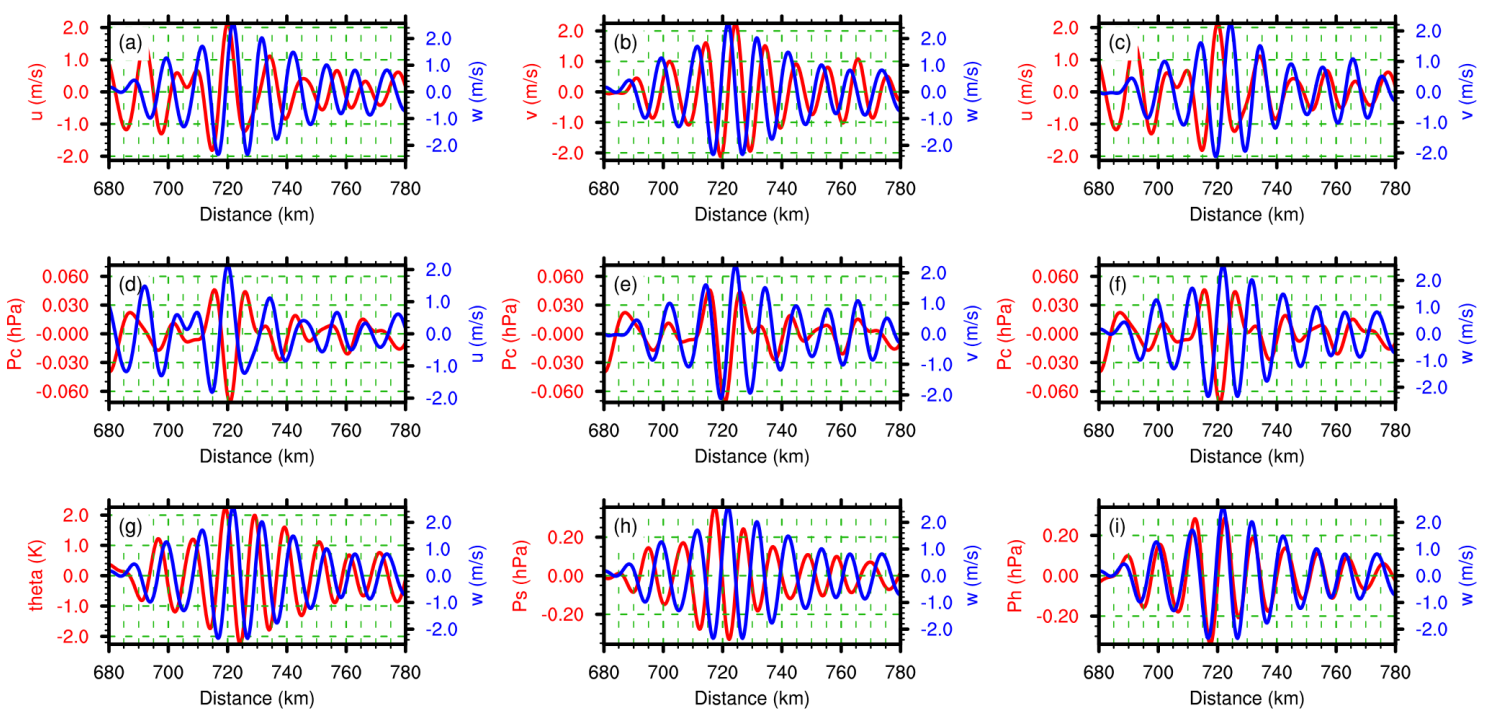

Figure 11. Same as in Fig. 8, but for an example of smaller-scale variations during segment J3 (680-780 km). The wavelet-based bandpass window is $8-16 \mathrm{~km}$.
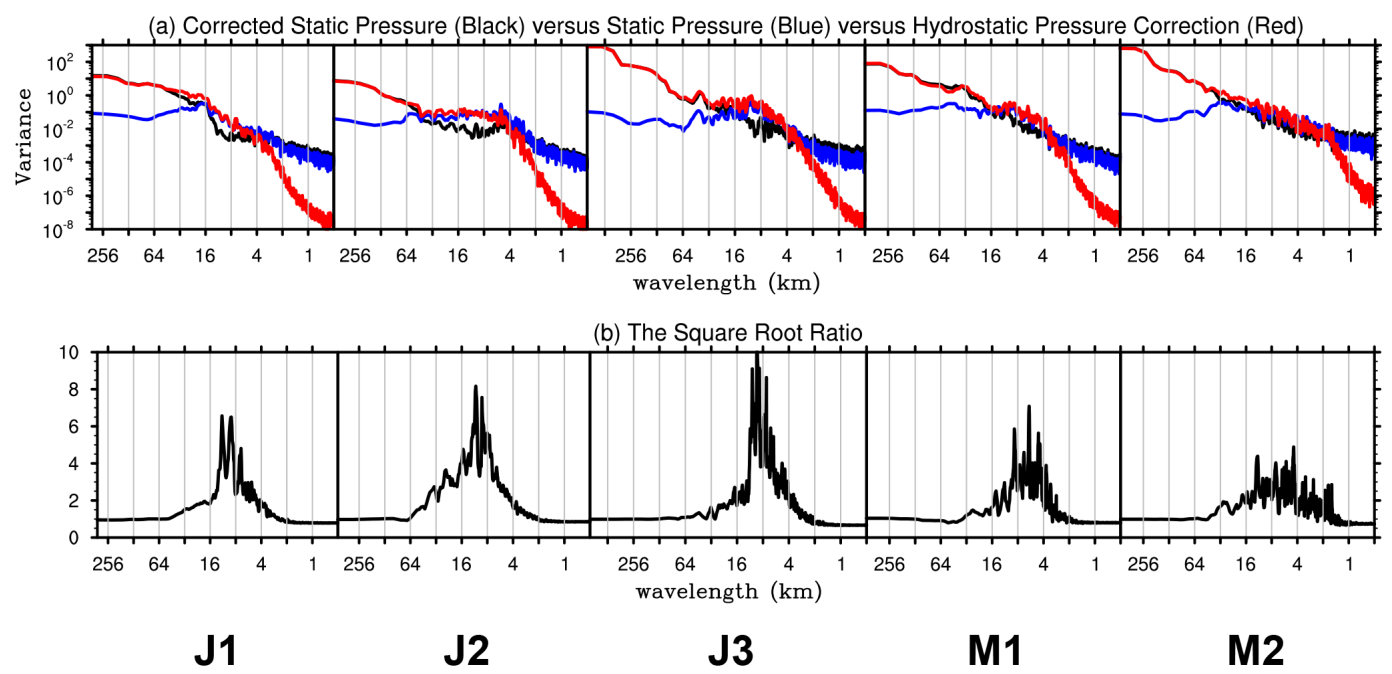

Figure 12. (a) The spectrum of corrected static pressure (black), static pressure (blue), and hydrostatic pressure correction (red) based on GV flight-level aircraft measurements during five selected segments (from left to right: J1, J2, J3, M1 and M2) of RF02 in START08. (b) The spectrum of the square root ratio (see the text for its definition).

than $\sim 4 \mathrm{~km}, p_{\mathrm{c}}$ is almost identical to $p_{\mathrm{s}}$. Figure $12 \mathrm{~b}$ shows the quantity $\sqrt{\frac{\operatorname{spec}\left(p_{\mathrm{s}}\right)+\operatorname{spec}\left(p_{\mathrm{h}}\right)}{\operatorname{spec}\left(p_{\mathrm{c}}\right)}}$, where $\operatorname{spec}()$ indicates the power spectrum of the variable inside the parentheses (e.g., Figs. 4 and 5). For segment $\mathrm{J} 3$, the square root of the ratio is close to 1.0 for the wavelengths greater than $\sim 32 \mathrm{~km}$ and less than $\sim 4 \mathrm{~km}$. At intermediate wavelengths, the square root of the ratio reaches a maximum near 10 for wavelengths of $\sim 10 \mathrm{~km}$. This suggests that $p_{\mathrm{s}}^{\prime}$ and $p_{\mathrm{h}}^{\prime}$ may tend to cancel each other at intermediate scales, which reduces the amplitude of $p_{\mathrm{c}}^{\prime}$ at these intermediate wavelengths (also see the example in Fig. 11) since $p_{\mathrm{c}}^{\prime}$ is the sum of $p_{\mathrm{s}}^{\prime}$ and $p_{\mathrm{h}}^{\prime}$. Similar behaviors can be also observed in other segments, although the exact ranges of the intermediate wavelengths may be different from case to case.

Figure 12 suggests that the assumption of constant $p_{\mathrm{S}}$ flight height may not be valid at all scales, though it appears to be true for mesoscale waves. In consequence, $p_{\mathrm{h}}^{\prime}$ may not always dominate over $p_{\mathrm{s}}^{\prime}$ as assumed in Smith et al. (2008). The spectral analysis and wavelet analysis of $p_{\mathrm{s}}$ (not shown) demonstrate that $p_{\mathrm{s}}$ indeed has relatively large variances for 
the short-scale range, and that $p_{\mathrm{s}}$ and $w$ share some common characteristics (also see Fig. 3). Moreover, the hydrostatic approximation, which is the underlying assumption for Eq. (1), may no longer be valid for short scales.

\section{Concluding remarks and discussion}

One of the primary objectives of the recent START08 field experiment is to characterize the sources and impacts of mesoscale waves with high-resolution flight-level aircraft measurements and mesoscale models. The current study focuses on the second research flight (RF02), which was the first airborne mission dedicated to probing gravity waves associated with strong upper-tropospheric jet-front systems and high topography. Based on spectral and wavelet analyses of the in situ observations, along with a diagnosis of the polarization relationships, it is found that there are clear signals of significant mesoscale variations with wavelengths ranging from $\sim 50$ to $\sim 500 \mathrm{~km}$ in almost every segment of the $8 \mathrm{~h}$ flight (order ranging from 0.01 to $1.0 \mathrm{~m} \mathrm{~s}^{-1}$ in vertical motion), which took place mostly in the lower stratosphere. The flow sampled by the aircraft covers a wide range of background conditions including near the jet core, a jet over the high mountains, and the exit region of the jet. There is clear evidence of vertically propagating gravity waves of alongtrack wavelengths between 100 and $120 \mathrm{~km}$ during some of the flight segments. There are also some indications of potential vertically trapped gravity waves of along-track wavelengths between 32 and $64 \mathrm{~km}$.

A general summary of power spectra is as follows. (1) Horizontal velocity components and potential temperature for the scale approximately between $\sim 8$ and $\sim 256 \mathrm{~km}$ display the approximate $-5 / 3$ power law. The common characteristics and individual features of the wave variances and spectrum slope behaviors appear to be generally consistent with past studies on the spectral analysis of aircraft measurements, including Nastrom and Gage (1985) using the Global Atmospheric Sampling Program (GASP) flight data set, and Lindborg (1999) using the Measurement of Ozone and Water Vapor by Airbus In-Service Aircraft (MOZAIC) aircraft observations. In addition, our recent separate study of idealized moist baroclinic waves (Sun and Zhang, 2015) suggests that the presence of moist convection and mesoscale gravity waves, though probably non-isotropic, does appear to steer the mesoscale range of the spectral slope to be $-5 / 3$. (2) The vertical velocity component appears to be flat approximately within the range between $\sim 8$ and $\sim 256 \mathrm{~km}$. (3) The power spectra of horizontal velocity components and potential temperature roll over to a -3 power law for the scale between $\sim 0.5$ and $\sim 8 \mathrm{~km}$. Based on three aircraft campaign projects, Bacmeister et al. (1996) has also reported the small-scale steepening behavior. The characteristics in (3) are generally observed except (4) when this part of the spectrum is activated, as recorded clearly by M2, one of the highlighted flight segments. Interestingly, the M1 segment immediately prior to the M2 segment did not record the event, probably due to the fast changing background flow. Spectral behaviors of atmospheric variables have also been studied by highresolution non-hydrostatic mesoscale numerical weather prediction (NWP) models (e.g., Skamarock, 2004; Tan et al., 2004; Zhang et al., 2007; Waite and Snyder, 2013; Bei and Zhang, 2014).

Smaller-scale wave-like oscillations below $50 \mathrm{~km}$ are found to be quite transient. In particular, aircraft measurements of several flight segments are dominated by signals with sampled periods of $\sim 20-\sim 60 \mathrm{~s}$ and wavelengths of $\sim 5-\sim 15 \mathrm{~km}$ (assuming that the typical flight speed is approximately $250 \mathrm{~m} \mathrm{~s}^{-1}$ ). This study suggests that at least part of the nearly periodic high-frequency signals might be unphysical and a result of intrinsic observational errors in the aircraft measurements or small-scale flight-altitude fluctuations that are difficult to account for. Such potentially contaminated variations are often collocated with larger-scale wave signals, which in turn may lead to larger uncertainties in the estimation of the wave characteristics. Part of the uncertainties may come from the inability of the aircraft to maintain constant static pressure altitude in the presence of small-scale turbulence. The current study mainly focuses on examining the fluctuations with the use of linear theory for monochromatic gravity waves. Therefore, in addition to measurement errors, the possibilities that those fluctuations may be due to other physical phenomena (e.g., nonlinear dynamics, shear instability and/or turbulence) cannot be completely ruled out in the current study.

Although the real-time mesoscale analysis and prediction system gave a reasonable forecast guidance on the region of potential gravity wave activities, it remains to be explored (1) how well the current generation of numerical weather models predicts the excitation of gravity waves, (2) how often gravity waves break in the ExUTLS region, and (3) what evidence in tracer measurements is shown for the contribution of gravity wave breaking to mixing. Future work will also seek to examine the origin and dynamics of the gravity waves observed during RF02 of START08 through a combination of observations and numerical modeling. This will help to distinguish whether the sampled mesoscale and small-scale variances are gravity waves or artifacts of the observing system. In addition, under the idealized controllable atmosphere with varying degrees of convective instability and baroclinic instability (e.g., Zhang, 2004; Wang and Zhang, 2007; Wei and Zhang, 2014; Sun and Zhang, 2015), high-resolution simulations of baroclinic jet-front systems will be employed to understand (1) how to constrain the parameterizations of jet-front gravity waves in general circulation models, (2) the role of gravity waves in mesoscale predictability, and (3) the contribution of gravity waves to mesoscale energy spectra in global wavenumber distribution or in multi-dimensional wavenumber distribution. 
Acknowledgements. The START08 experiment is sponsored by the National Science Foundation (NSF). A large number of people contributed to the success of START08 experiment. The dedication of the instrument team, co-sponsored by NCAR, University of Colorado, Harvard University, University of Miami, Princeton University, NOAA Earth System Research Laboratory (ESRL) Global Monitoring Division (GMD) and Chemical Science Division (CSD), and the NCAR Research Aviation Facility staff in running the flight operation are the key factors in the success of the campaign. We also acknowledge the effort and skill of the GV pilots Henry Boynton and Ed Ringleman, which was critical to meeting mission objectives. We benefited from review comments from the editor Tim Dunkerton and four anonymous reviewers on an earlier version of the manuscript. This research is sponsored by NSF grants 0618662, 0722225, 0904635, and 1114849. Computing is performed at the Texas Advanced Computing Center (TACC).

Edited by: T. J. Dunkerton

\section{References}

Alexander, M. J. and Rosenlof, K. H.: Gravity-wave forcing in the stratosphere: Observational constraints from the Upper Atmosphere Research Satellite and implications for parameterization in global models, J. Geophys. Res.-Atmos., 108, 4597, doi:10.1029/2003JD003373, 2003.

Bacmeister, J. T., Eckermann, S. D., Newman, P. A., Lait, L., Chan, K. R., Loewenstein, M., Proffitt, M. H., and Gary, B. L.: Stratospheric horizontal wavenumber spectra of winds, potential temperature, and atmospheric tracers observed by high-altitude aircraft, J. Geophys. Res., 101, 9441-9470, 1996.

Bei, N. and Zhang, F.: Mesoscale Predictability of Moist Baroclinic Waves: Variable and Scale Dependent Error Growth, Adv. Atmos. Sci., 31, 995-1008, doi:10.1007/s00376-014-3191-7, 2014.

Bertin, F., Campistron, B., Caccia, J. L., and Wilson, R.: Mixing processes in a tropopause folding observed by a network of ST radar and lidar, Ann. Geophys., 19, 953-963, doi:10.5194/angeo19-953-2001, 2001.

Bosart, L. F., Bracken, W. E., and Seimon, A.: A study of cyclone mesoscale structure with emphasis on a large-amplitude inertiagravity waves, Mon. Weather Rev., 126, 1497-1527, 1998.

Brown, P. R. A.: Aircraft measurements of mountain waves and their associated momentum flux over the british isles, Q. J. Roy. Meteor. Soc., 109, 849-865, 1983.

Charney, J. G.: Geostrophic turbulence, J. Atmos. Sci., 28, 10871095, 1971.

Donoho, D. L. and Johnstone, I. M.: Ideal spatial adaptation by wavelet shrinkage, Biometrika, 81, 425-455, 1994.

Dornbrack, A., Birner, T., Fix, A., Flentje, H., Meister, A., Schmid, H., Browell, E. V., and Mahoney, M. J.: Evidence for inertia gravity waves forming polar stratospheric clouds overscandinavia, J. Geophys. Res., 107, 8287, doi:10.1029/2001JD000452, 2002.

Doyle, J., Volkert, H., Dornbrack, A., Hoinka, K., and Hogan, T.: Aircraft measurementsand numerical simulations of mountain waves over the central Alps: A pre-MAP test case, Q. J. Roy. Meteor. Soc., 128, 2175-2184, 2002.

Einaudi, F., Bedard, A. J., and Finnigan, J. J.: A climatology of gravity waves and other coherent disturbances at the Boulder Atmo- spheric Observatory during March-April 1984, J. Atmos. Sci., 46, 303-329, 1989.

Eliassen, A. and Palm, E.: On the transfer of energy in stationary mountain waves, Geofys. Publ., 22, 1-23, 1960.

Farge, M.: Wavelet transforms and their applications to turbulence, Annu. Rev. Fluid Mech., 24, 395-457, 1992.

Fritts, D. C. and Nastrom, G. D.: Sources of mesoscale variability of gravity waves. Part II: Frontal, convective, and jet stream excitation, J. Atmos. Sci., 49, 111-127, 1992.

Gong, J. and Geller, M. A.: Vertical fluctuation energy in United States high vertical resolution radiosonde data as an indicator of convective gravity wave sources, J. Geophys. Res. 115, D11110, doi:10.1029/2009JD012265, 2010.

Grivet-Talocia, S., Einaudi, F., Clark, W. L., Dennett, R. D., Nastrom, G. D., and VanZandt, T. E.: A 4-yr Climatology of Pressure Disturbances Using a Barometer Network in Central Illinois, Mon. Weather Rev., 127, 1613-1629, 1999.

Grubišić, V., Doyle, J. D., Kuettner, J., Mobbs, S., Smith, R. B., Whiteman, C. D., Dirks, R., Czyzyk, S., Cohn, S. A., Vosper, S., Weissmann, M., Haimov, S., De Wekker, S. F. J., Pan, L. L., and Chow, F. K.: The Terrain-Induced Rotor Experiment, B. Am. Meteorol. Soc., 89, 1513-1533, 2008.

Hertzog, A. and Vial, F.: A study of the dynamics of the equatorial lower stratosphere by use of ultra-long-duration balloons: 2 . Gravity waves, J. Geophys. Res., 106, 22745-22761, 2001.

Jensen, E. J., Starr, D., and Toon, O. B.: Mission investigates tropical cirrus clouds, EOS, 85, 45-50, 2004.

Kaplan, M. L., Koch, S. E., Lin, Y.-L., Weglarz, R. P., and Rozumalski, R. A.: Numerical simulations of a gravity wave event over CCOPE. Part I: The role of geostrophic adjustment in mesoscale jetlet formation, Mon. Weather Rev., 125, 1185-1211, 1997.

Karacostas, T. S. and Marwitz, J. D.: Turbulent kinetic energy budgets over mountainousterrain, J. Appl. Meteor., 19, 163-174, 1980.

Koch, S. E., Zhang, F., Kaplan, M., Lin, Y.-L., Weglarz, R., and Trexler, M.: Numerical simulation of a gravity wave event observed during ccope. part 3: the role of a mountain-plains solenoid in the generation of the second wave episode, Mon. Weather Rev., 129, 909-932, 2001.

Koch, S. E., Jamison, B. D., Lu, C. G., Smith, T. L., Tollerud, E. I., Girz, C., Wang, N., Lane, T. P., Shapiro, M. A., Parrish, D. D., and Cooper, O. R.: Turbulence and gravity waves within an upper-level front, J. Atmos. Sci., 62, 3885-3908, 2005.

Kolmogorov, A. N.: The local structure of turbulence in incompressible viscous fluid for very large Reynolds number, Dokl. Akad. Nauk SSSR, 30, 301-305, 1941.

Koppel, L. L., Bosart, L. F., and Keyser, D.: A 25-yr climatology of large-amplitude hourly surface pressure changes over the conterminous United States, Mon. Weather Rev., 96, 51-68, 2000.

Kraichnan, R. H.: Inertial ranges in two-dimensional turbulence, Phys. Fluids, 10, 1417-1423, 1967.

Lane, T. P., Reeder, M. J., and Clark, T. L.: Numerical Modeling of Gravity Wave Generation by Deep Tropical Convection, J. Atmos. Sci., 58, 1249-1274, 2001.

Lane, T. P., Doyle, J. D., Plougonven, R., Shapiro, M. A., and Sharman, R. D.: Observations and numerical simulations of inertiagravity waves and shearing instabilities in the vicinity of a jet stream, J. Atmos. Sci., 61, 2692-2706, 2004. 
Laursen, K. K., Jorgensen, D. P., Brasseur, G. P., Ustin, S. L., and Huning, J. R.: HIAPER: The next generation NSF/NCAR research aircraft, B. Am. Meteorol. Soc., 87, 896-909, 2006.

Leutbecher, M. and Volkert, H.: The propagation of mountain waves into the stratosphere: Quantitative evaluation of threedimensional simulations, J. Atmos. Sci., 57, 3090-3108, 2000.

Lilly, D. K. and Kennedy, P. J.: Observations of a stationary mountain wave and it sassociated momentum flux and energy dissipation, J. Atmos. Sci., 30, 1135-1152, 1973.

Lin, Y. and Zhang, F.: Tracking gravity waves in baroclinic jet-front systems, J. Atmos. Sci., 65, 2402-2415, 2008.

Lindborg, E.: Can the atmospheric kinetic energy spectrum be explained by two-dimensional turbulence?, J. Fluid Mech., 388, 259-288, 1999.

Lindzen, R. S.: Dynamics in Atmospheric Physics, Cambridge University Press, Cambridge, UK, 320 pp., 1990.

Meng, Z. and Zhang, F.: Test of an ensemble-Kalman filter for mesoscale and regional-scale data assimilation. Part III: Comparison with 3Dvar in a real-data case study, Mon. Weather Rev., 136, 522-540, 2008a.

Meng, Z. and Zhang, F.: Test of an ensemble-Kalman filter for mesoscale and regional-scale data assimilation. Part IV: Performance over a warm-season month of June 2003, Mon. Weather Rev., 136, 3671-3682, 2008b.

Mirzaei, M., Zülicke, C., Mohebalhojeh, A., Ahmadi-Givi, F., and Plougonven, R.: Structure, energy, and parameterization of inertia-gravity waves in dry and moist simulations of a baroclinic wave life cycle, J. Atmos. Sci., 71, 2390-2414, doi:10.1175/JASD-13-075.1, 2014.

Moustaoui, M., Teitelbaum, H., van Velthoven, P. F. J., and Kelder, H.: Analysis of gravity waves during the POLINAT experiment and some consequences for stratosphere-troposphere exchange, J. Atmos. Sci., 56, 1019-1030, 1999.

Nastrom, G. D. and Fritts, D. C.: Sources of mesoscale variability of gravity waves. Part I: Topographic excitation, J. Atmos. Sci., 49, 101-110, 1992.

Nastrom, G. D. and Gage, K. S.: A Climatology of Atmospheric Wavenumber Spectra of Wind and Temperature Observed by Commercial Aircraft, J. Atmos. Sci., 42, 950-960, 1985.

O'Sullivan, D. and Dunkerton, T. J.: Generation of inertia-gravity waves in a simulated life cycle of baroclinic instability, J. Atmos. Sci., 52, 3695-3716, 1995.

Pan, L. L., Bowman, K. P., Atlas, E. L., Wofsy, S. C., Zhang, F., Bresch, J. F., Ridley, B. A., Pittman, J. V., Homeyer, C. R., Romashkin, P., and Cooper, W. A.: The Stratosphere-Troposphere Analyses of Regional Transport 2008 Experiment, B. Am. Meteorol. Soc., 91, 327-342, 2010.

Pavelin, E., Whiteway, J. A., and Vaughan, G.: Observation of gravity wave generation and breaking in the lowermost stratosphere, J. Geophys. Res., 106, 5173-5179, 2001.

Plougonven, R. and Snyder, C.: Inertia-gravity waves spontaneously generated by jets and fronts. Part I: Different baroclinic life cycles, J. Atmos. Sci., 64, 2502-2520, 2007.

Plougonven, R. and Zhang, F.: Internal gravity waves from atmospheric jets and fronts, Rev. Geophys., 52, 33-76, doi:10.1002/2012RG000419, 2014.

Plougonven, R., Teitelbaum, H., and Zeitlin, V.: Inertia gravity wave generation by tropospheric midlatitude jet as given by the fronts and atlantic storm-track experiment radio soundings, J. Geophys. Res.-Atmos., 108, 888-889, 2003.

Pokrandt, P. J., Tripoli, G. J., and Houghton, D. D.: Processes leading to the formation of mesoscale waves in the midwest cyclone of 15 December 1987, Mon. Weather Rev., 124, 2726-2752, 1996.

Poulos, G. S., Blumen, W., Fritts, D. C., Lundquist, J. K., Sun, J., Burns, S. P., Nappo, C., Banta, R., Newsom, R., Cuxart, J., Terradellas, E., Balsley, B., and Jensen, M.: CASES-99: A Comprehensive Investigation of the Stable Nocturnal Boundary Layer, B. Am. Meteorol. Soc., 83, 555-581, 2002.

Powers, J. G. and Reed, R. J.: Numerical model simulation of the large-amplitude mesoscale gravity-wave event of 15 December 1987 in the central United States, Mon. Weather Rev., 121, 22852308, 1993.

Radok, U.: A procedure for studying mountain effects at low levels, B. Am. Meteorol. Soc., 35, 412-416, 1954.

Ramamurthy, M. K., Rauber, R. M., Collins, B., and Malhotra, N. K.: A comparative study of large-amplitude gravity-wave events, Mon. Weather Rev., 121, 2951-2974, 1993.

Rauber, R. M., Yang, M., Ramamurthy, M. K., and Jewett, B. F.: Origin, evolution, and fine-scale structure of the St. Valentine's Day mesoscale gravity wave observed during storm-fest. Part I: Origin and evolution, Mon. Weather Rev., 129, 198-217, 2001.

Reeder, M. J. and Griffiths, M.: Stratospheric inertia-gravity waves generated in a numerical model of frontogenesis. II: Wave sources, generation mechanisms and momentum fluxes, Q. J. Roy. Meteor. Soc., 122, 1175-1195, 1996.

Schneider, R. S.: Large-amplitude mesoscale wave disturbances within the intense midwest extratropical cyclone of 15 December 1987, Weather Forecast., 5, 533-558, 1990.

Shapiro, M. A. and Kennedy, P. J.: Aircraft Measurements of Wave Motions within Frontal Zone Systems, Mon. Weather Rev., 103, 1050-1054, doi:10.1175/15200493(1975)103<1050:AMOWMW>2.0.CO;2, 1975.

Skamarock, W. C.: Evaluating Mesoscale NWP Models Using Kinetic Energy Spectra, Mon. Weather Rev., 132, 3019-3032, 2004.

Skamarock, W. C., Klemp, J. B., Dudhia, J., Gill, D. O., Barker, D. M., Wang, W., and Powers, J. G.: A description of the Advanced Research WRF Version 2. NCAR technical note 468+STR, National Center For Atmospheric Research (NCAR), Boulder, Colorado, USA, 88 pp., 2005.

Smith, R. B.: The generation of lee waves by the blue ridge, J. Atmos. Sci., 33, 507-519, 1976.

Smith, R. B.: Linear theory of stratified hydrostatic flow past an isolated mountain, Tellus, 32, 348-364, 1980.

Smith, R. B., Woods, B. K., Jensen, J., Cooper, W. A., Doyle, J. D., Jiang, Q., and Grubisic, V.: Mountain waves entering the stratosphere, J. Atmos. Sci., 65, 2543-2562, 2008.

Sun, Y. Q. and Zhang F.: Intrinsic vs. practical limits of atmospheric predictability and the significance of the butterfly effect, J. Atmos. Sci., in revision, 2015.

Tan, Z. M., Zhang, F., Rotunno, R., and Snyder, C.: Mesoscale predictability of moist baroclinic waves: Experiments with parameterized convection, J. Atmos. Sci., 61, 1794-1804, 2004.

Torrence, C. and Compo, G. P.: A practical guide to wavelet analysis, B. Am. Meteorol. Soc., 19, 61-78, 1998. 
Uccellini, L. W. and Koch, S. E.: The synoptic setting and possible source mechanisms for mesoscale gravity wave events, Mon. Weather Rev., 115, 721-729, 1987.

Vaughan, G. and Worthington, R. M.: Break-up of a stratospheric streamer observed by MST radar, Q. J. Roy. Meteor. Soc., 126, 1751-1769, 2000.

Vaughan, G. and Worthington, R. M.: Inertia-gravity waves observed by the UK MST radar, Q. J. Roy. Meteor. Soc., 133, 179$188,2007$.

Vergeiner, I. and Lilly, D. K.: The dynamic structure of lee wave flow as obtained from balloon and airplane observations, Mon. Weather Rev., 98, 220-232, 1970.

Vincent, R. A. and Alexander, M. J.: Gravity waves in the tropical lower stratosphere: An observational study of seasonal and interannual variability, J. Geophys. Res., 105, 17971-17982, 2000.

Waite, M. L. and Snyder, C.: Mesoscale Energy Spectra of Moist Baroclinic Waves, J. Atmos. Sci., 70, 1242-1256, 2013.

Wang, L. and Geller, M. A.: Morphology of gravity-wave energy as observed from 4 years (1998-2001) of high vertical resolution U.S. radiosonde data, J. Geophys. Res., 108, 4489, doi:10.1029/2002JD002786, 2003.

Wang, L., Alexander, M. J., Bui, T. B., and Mahoney, M. J.: Smallscale gravity waves in ER-2 MMS/MTP wind and temperature measurements during CRYSTAL-FACE, Atmos. Chem. Phys., 6, 1091-1104, doi:10.5194/acp-6-1091-2006, 2006.

Wang, S. and Zhang, F.: Sensitivity of mesoscale gravity waves to the baroclinicity of jet-front systems, Mon. Weather Rev., 135, 670-688, 2007.

Wei, J. and Zhang, F.: Mesoscale gravity waves in moist baroclinic jet-front systems, J. Atmos. Sci., 71, 929-952, doi:10.1175/JASD-13-0171.1, 2014.

Wei, J. and Zhang, F.: Tracking gravity waves in moist baroclinic jet-front systems, Journal of Advanced Modeling in Earth Sciences (JAMES), 7, 67-91, doi:10.1002/2014MS000395, 2015.

Woods, B. K. and Smith, R. B.: Energy flux and wavelet diagnostics of secondary mountain waves, J. Atmos. Sci., 67, 3721-3738, 2010.

Woods, B. K. and Smith, R. B.: Short-Wave Signatures of Stratospheric Mountain Wave Breaking, J. Atmos. Sci., 68, 635-656, 2011.

Wu, D. L. and Zhang, F.: A study of mesoscale gravity waves over the North Atlantic with satellite observations and a mesoscale model, J. Geophys. Res.-Atmos., 109, D22104, doi:10.1029/2004JD005090, 2004.
Yamanaka, M. D., Ogino, S., Kondo, S., Shimomai, T., Fukao, S., Shibagaki, Y., Maekawa, Y., and Takayabu, I.: Inertio-gravity waves and subtropical multiple tropopauses: vertical wavenumber spectra of wind and temperature observed by the MU radar, radiosondes and operational rawinsonde network, J. Atmos. Terr. Phys., 58, 785-805, 1996.

Zhang, F.: Generation of mesoscale gravity waves in the uppertropospheric jet-front systems, J. Atmos. Sci., 61, 440-457, 2004.

Zhang, F. and Koch, S. E.: Numerical simulation of a gravity wave event over CCOPE. Part II: Wave generated by an orographic density current, Mon. Weather Rev., 128, 2777-2796, 2000.

Zhang, F., Koch, S. E., Davis, C. A., and Kaplan, M. L.: Wavelet analysis and the governing dynamics of a large-amplitude gravity wave event along the east coast of the United States, Q. J. Roy. Meteor. Soc., 127, 2209-2245, 2001.

Zhang, F., Koch, S. E., and Kaplan, M. L.: Numerical simulations of a large-amplitude gravity wave event, Meteorol. Atmos. Phys., 84, 199-216, 2003.

Zhang, F., Wang, S., and Plougonven, R.: Uncertainties in using the hodograph method to retrieve gravity wave characteristics from individual soundings, Geophys. Res. Lett., 31, L11110, doi:10.1029/2004GL019841, 2004.

Zhang, F., Meng, Z., and Aksoy, A.: Tests of an ensemble Kalman filter for mesoscale and regional-scale data assimilation. Part I: Perfect model experiments, Mon. Weather Rev., 134, 722-736, 2006.

Zhang, F., Bei, N., Rotunno, R., Snyder, C., and Epifanio, C. C.: Mesoscale predictability of moist baroclinic waves: Convectionpermitting experiments and multistage error growth dynamics, J. Atmos. Sci., 64, 3579-3594, 2007.

Zhang, F., Zhang, M., Wei, J., and Wang, S.: Month-Long Simulations of Gravity Waves over North America and North Atlantic in Comparison with Satellite Observations, Acta Meteorol. Sin., 27, 446-454, 2013.

Zhang, S. D. and Yi, F.: Latitudinal and seasonal variations of inertial gravity wave activity in the lower atmosphere over central China, J. Geophys. Res., 112, D05109, doi:10.1029/2006JD007487, 2007. 